\title{
Article
}

\section{Can Decentralization Drive Green Innovation? A Game Theoretical Analysis of Manufacturer Encroachment Selection with Consumer Green Awareness}

\author{
Dan Cao ${ }^{1}$, Jin $\mathrm{Li}^{2}$, Gege Liu ${ }^{2}$ and Ran Mei ${ }^{3, *}$ \\ 1 School of Business Administration, Zhejiang Gongshang University, Hangzhou 310018, China; \\ cd@mail.zjgsu.edu.cn \\ 2 School of Management and E-Business, Modern Business Research Center, Key Research Institute, \\ Zhejiang Gongshang University, Hangzhou 310018, China; jinli@mail.zjgsu.edu.cn (J.L.); \\ lgg979492@163.com (G.L.) \\ 3 School of Economics and Management, Tongji University, Shanghai 200092, China \\ * Correspondence: 1610334@tongji.edu.cn
}

check for updates

Citation: Cao, D.; Li, J.; Liu, G.; Mei, R. Can Decentralization Drive Green Innovation? A Game Theoretical Analysis of Manufacturer

Encroachment Selection with Consumer Green Awareness. Processes 2021, 9, 990. https:// doi.org/10.3390/pr9060990

Academic Editor: Anet Režek Režek Jambrak

Received: 10 May 2021

Accepted: 31 May 2021

Published: 3 June 2021

Publisher's Note: MDPI stays neutral with regard to jurisdictional claims in published maps and institutional affiliations.

Copyright: (c) 2021 by the authors. Licensee MDPI, Basel, Switzerland. This article is an open access article distributed under the terms and conditions of the Creative Commons Attribution (CC BY) license (https:/ / creativecommons.org/licenses/by/ $4.0 /)$.

\begin{abstract}
With the increase of public environmental awareness and the growth of e-commerce, sustainable development promotes the manufacturer to increasingly participate in green innovation and make full use of the online sales channel to enhance competitiveness. Despite decentralized encroachment being widely adopted in business reality, the current literature has commonly paid more attention to centralized encroachment. To complement related research, a dual-channel green supply chain composed of a manufacturer (its retail subsidiary) and a retailer is investigated. We focus on what encroachment strategy (centralization vs. decentralization) drives the green innovation and analyze the impact of consumer green awareness and product substitutability on the manufacturer's encroachment strategy, green innovation efforts and supply chain performance. Under each encroachment strategy, we build a Stackelberg game model and derive the equilibrium outcome. Then, we theoretically analyze the effects of consumer green awareness and product substitutability on green innovation and each party's profitability. Our comparative analysis shows what encroachment strategy drives green innovation and what encroachment strategy benefits both parties and social welfare. Numerical studies are also conducted to support the analytical results. Our key findings reveal that decentralization improves the green innovation and achieves a both-win situation for the manufacturer and the retailer. Besides that, decentralization can reduce the environmental damage and increase social welfare as well.
\end{abstract}

Keywords: green innovation; manufacturer encroachment; consumer green awareness; substitutability

\section{Introduction}

In recent years, environmental damage and deterioration issues, such as air and water pollution, greenhouse effect, climate change, landfill waste, acidic rains and noise pollution, have been widely concerned by lots of the countries in the world. These environmental hazards are increasingly threatening human health and survival. To address these environmental issues, both governments and firms all over the world have taken action. According to UK Climate Change Act schedules, the target of $80 \%$ reduction by 2050 in greenhouse gas emissions has been set up. The government in China plans for a $40-45 \%$ reduction in its carbon emissions per-unit GDP by 2025 compared to its 2005 level [1]. Many famous firms including Wal-Mart, M\&S, Tesco and Debenhams take various measures to reduce their own and suppliers' carbon footprint in raw material sourcing, production, logistics and retailing [2].

Green supply chain can be defined as enhancing the overall environmental protection awareness of the supply chain and promoting the improvement of economic and social 
benefits by utilizing resources in the whole process from production to sales [3]. In addition to traditional supply chain management activities, green supply chain management (GSCM) puts more emphasis on reducing the harm of its operation to environment and human health [4]. Many researchers all over the world are devoted to investigating GSCM and green innovation involving various factors, such as green planning, green product design, green manufacturing, by-products use and reverse logistics $[5,6]$. In the context of environmental protection, green (environmental-friendly) products with appropriate quality and lowest negative effect on the environment have been manufactured [7]. In addition, lots of manufacturers are willing to make green innovation efforts to improve the supply chain greenness, e.g., producing new green products, developing green technologies and using new clean energy to reduce pollutants. For example, Pepsi Cola, a giant beverage manufacturer, makes use of advanced green technology to replace corrugated materials with reusable plastic containers to reduce environmental pollution [8]. Green innovation activities can establish better social image for supply chain members and improve their core competitiveness by reducing its harm on the environment.

Compared with non-green products, green products are environmentally friendly but paid at a higher price as well. The reason is that, for a manufacturer, it will cost more to produce green products, which makes green products more expensive [9]. Intuitively, the manufacturer implements green innovation activities in the production of green products only when their benefits exceed the production costs. The key to the problem is whether consumers are willing to pay a sufficiently high premium to offset the additional costs. Fortunately, there is plenty of evidence showing that environmentally aware consumers prefer green products and are willing to pay higher price than non-green ones. StarKist tuna reports that consumers are willing to buy dolphin safe tuna at a $\$ 0.21$ higher price per can than regular one [10]. A survey by Bureau of Energy in Taiwan reveals that 50\% of the respondents in nine developed countries prefer eco-labelled products, which are produced with the aim of supporting consumer decision-making for environmentally friendly products by providing transparency and enhancing trust in the environmental identities of products [11], and $24 \%$ of them would like to pay a premium price for these green products [12]. In this sense, consumer's stronger willingness to pay for green products will enhance the demand and then incentive the manufacturer to adopt more green innovations.

With the fierce market competition and rapid growth of e-commerce business, to stay competitive and increase demand and profits, many traditional manufacturers have established online direct sale channels. For example, Samsung and LG sell their mobile phones through online stores as well as their offline retailers, which is known as a dualchannel supply chain [13]. Specifically, the direct channel often causes a conflict between the manufacturer and the retailer, which is referred as manufacturer encroachment [14].

So far, there are two encroachment strategies: centralized encroachment and decentralized encroachment. Under centralized encroachment, the manufacturer centrally makes all decisions (e.g., pricing) for her subsidiary in direct channel. In contrast, the manufacturer under decentralized encroachment will grant more decision-making power to her retail subsidiary. As an example, Sony Corporation allows its retail subsidiary, StylingLife Holdings (a holding company for Sony's group of retail businesses), to manage their own retail businesses independently [15]. Centralized encroachment usually leads to excessive vertical competition and inflexible trade between the manufacturer and the retailer [16,17]. Decentralized encroachment is hoped to improve the dual-channel interactions and address these concerns. Arya et al. [18] show that decentralized encroachment for a manufacturer can soften the retail competition by setting a transfer price above marginal cost to her downstream subsidiary, which increases the wholesale price and eventually benefits the manufacturer. In this paper, we will focus on these two types of manufacturer encroachment strategies in the presence of green innovation.

An incentive has arisen to incorporate green innovation into the study of manufacturer encroachment, where a manufacturer makes green innovation efforts to produce green 
products and sells them in dual channels. In the mobile phones industry, Nokia uses materials with no toxic flame retardants to produce mobile phones and accessories and then sells them through both retailers and their own physical/online stores [19]. For green products, some key factors should be investigated, such as consumer green awareness and manufacturer's green innovation efforts. As mentioned earlier, consumer green awareness will affect the demand and pricing decisions. The manufacturer makes green innovation efforts to improve the environment performance and attract more customers, but it also incurs more manufacturing and design/production costs. Therefore, the manufacturer attempts to decide an optimal level of green innovation efforts to balance the gains from the consumer's demand with green awareness and the losses from green innovation investment. On the other hand, since the manufacturer's encroachment usually causes the channel conflicts, the manufacturer also needs to determine the pricing through a deliberate trade-off between the profits in both channels. Moreover, to examine the effect of the channel conflicts between the manufacturer and the retailer, we will consider the product substitutability across the two channels.

The primary goal of this paper is to study what encroachment strategy (centralization vs. decentralization) drives the green innovation and analyze the impact of consumer green awareness and product substitutability on the manufacturer's encroachment strategy, green innovation efforts and supply chain performance. Based on extant literature, these issues are not yet fully addressed. To fill this important research gap, we build a Stackelberg game model in a two-echelon supply chain with a green manufacturer and a retailer. The manufacturer produces green products and directly sells them to end consumers through her subsidiary, which may be centralized or decentralized with the manufacturer. In these settings, the subsidiary will compete with the retailer selling substitutable green products.

We contribute to the literature in the following three ways. First, in terms of modelling, we contribute to the dual-channel literature by incorporating green innovation, competition and consumer green awareness into game-theoretic models of manufacturer's encroachment. The analytical results show that as consumer green awareness increases, the manufacturer is motivated to improve green innovation efforts, which in turn benefits both the manufacturer and the retailer. Nevertheless, the higher product substitutability will reduce the level of the manufacturer's green innovation efforts. Accordingly, each firm's profit will decrease unless the encroachment cost exceeds a threshold. Second, unlike most existing studies considering centralized encroachment only, this paper contributes to the GSCM literature by allowing the manufacturer to choose between centralized and decentralized encroachment. Third, our research of this paper shows how the manufacturer makes a choice between centralized and decentralized encroachments when making green innovation efforts in dual channels. Our main findings reveal that decentralized encroachment outperforms centralized encroachment in the level of green innovation efforts and both members' profitability. Moreover, decentralized encroachment can also reduce the environmental damage and improve the social welfare.

The structure of this paper is organized as follows. Section 2 reviews relevant literature. Section 3 describes the basic assumptions and supply chain model for a manufacturer using centralized and decentralized encroachment. In Section 4, we derive the equilibriums under centralized and decentralized encroachments. Section 5 compares these two strategies. In Section 6, numerical studies are performed to verify the main findings. Finally, Section 7 summarizes the paper and puts forward suggestions for operations management and future research.

\section{Literature Review}

There are three streams of literature related to our study: green supply chain management, dual-channel supply chain and manufacturer encroachment. These are briefly reviewed below.

With the development of green supply chain management, many scholars have begun to study green supply chains from different perspectives. For example, Liu et al. [20] used 
game theory to study the influence of green preference coefficient and competitiveness on the decision-making of supply chain members in the situations of no competition, manufacturer competition and manufacturer-retailer competition. Green et al. [21] discovered that green supply chain management could promote economic development, improve ecological environment and enhance the competitiveness of manufacturer to some extent. Ghosh and Shah [22] studied the influence of the consumer green preference coefficient on the decision-making of supply chain members in the two-level green supply chain under the conditions of manufacturer led, retailer led and Nash equilibrium. He et al. [23] explored the effects of consumer preference characteristics on the green innovation efforts of the food supply chain, and they found that the change in consumer preference characteristics is an important factor to motivate supply chain members to make green innovation efforts. Liu et al. [24] pointed that the market demand for green products is not only related to product price but also to consumers' low-carbon preference. Lee [25] suggested that the supply chain members must participate in green innovation activities at the same time to achieve a win-win scenario in the CLSC. However, the above literature shows that the studies on the green supply chain mainly concentrate on product pricing, green innovation and consumers' green preference. Moreover, in the above literature, dual-channel is not involved.

The existing dual-channel green supply chain research mainly focused on the pricing, green production issues and channel competition, rarely considering the consumer green awareness. Cai [26] studied the channel selection and coordination of dual-channel supply chains and concluded that the operating costs of channels, the substitutability of channels and the overall profit of the supply chain will affect the channel selection decisions of suppliers and retailers. Heydari et al. [27] employed a Stackelberg game method to research the optimal pricing decision and coordination strategies for a green supply chain considering the introduction of online channel. Li et al. [8] presented a model to analyze green production and the pricing of the members in decentralized and centralized decision scenarios employing the Stackelberg game method. The results demonstrated when customers' loyalty to retail channel and green cost meet certain conditions, it is beneficial for both sides to develop direct channel.

Different from the above research, our work will focus on the analysis of consumers' green preference and products' substitutability of a dual-channel green supply chain under different manufacturer's encroachment strategies. Many researchers claimed that due to the aggravation of market competition, encroachment will reduce the retailers' profit [28], but some other scholars disagreed with this. For example, by reducing double marginalization, both the manufacturers and the retailers will benefit $[29,30]$. In the situation of quantity competition, Arya et al. [18] pointed out that a right transfer price set by the manufacturers can convey a less aggressive message to the retailers, which can effectively reduce the retailers' profit loss. Yoon [13] pointed out that the manufacturer encroachments do not always pose a threat to the retailers; when the manufacturers participate in retail, the manufacturers will lower their costs and set lower wholesale prices to the retailer. However, manufacturer encroachment did cause channel conflict. When the demand information is asymmetric [31], the retailers can hardly benefit from the direct sales channel of the suppliers. Ha et al. [32] pointed out that when the quality is endogenous and the manufacturers have enough flexibility in adjusting the quality, the encroachment is unfavorable for the retailers.

This paper is also closely related to the study of Arya et al. [18]. From their model, the retailer has advantages in sales because the retailer is more direct contact with consumers than the manufacturer. The manufacturer will choose a strategy without encroachment when the cost is too high. Besides, we study the decision-makings of green manufacturer under the encroachment. We focus on what encroachment drives green innovation and the analysis of the impacts of consumer green awareness and channel competitiveness on each party's profitability and total social welfare. 
In summary, this paper is different from the previous literature in three aspects. First, we take the consumer green awareness and channel competitiveness into account in the dual-channel green supply chain model. Second, we analyze whether the decentralization strategy with transfer pricing can alleviate the retailer's revenue loss under the manufacturer's encroachment. The results show that decentralization with an appropriate transfer pricing in a dual-channel green supply chains can drive green innovations and benefit both the retailer and the manufacturer. Third, we analyze and compare the two encroachment strategies' decision-making, profits, environmental damage and social welfare.

\section{Model Formulation}

\subsection{Model Description}

We consider a dual-channel green supply chain consisting of a manufacturer (he/him) and a retailer (she/her). The manufacturer has one upstream (manufacturing and wholesale) subsidiary and a downstream (retail) subsidiary. The upstream manufacturing subsidiary makes green innovation (such as developing and using green technologies) and provides differentiated green products, namely, product $d$ and product $r$, to the downstream subsidiary and the retailer, respectively. The two downstream parties then sell final products to end markets. They engage in a Cournot competition in the retail market. The manufacturer can choose between two encroachment strategies: centralized and decentralized encroachments. Under centralized encroachment, the manufacturer produces green products and sells them directly to the consumers in addition to wholesaling them to the retailer. Under decentralized encroachment, the manufacturer sells green products to its subsidiary with a transfer price, where the subsidiary can make its own sale decisions for maximizing its profit. This paper focuses on the impact of consumer green awareness and product competition on the manufacturer's green innovation and the choice of encroachment strategies.

To facilitate the expression, the superscripts $C$ and $D$ stand for equilibriums under centralized and decentralized encroachments. We use the subscripts $r, d$ and $m$ to represent the retailer, subsidiary, and manufacturer, respectively. The decision variables and parameters used in this paper are shown in Table 1.

Table 1. Notations list.

\begin{tabular}{cc}
\hline Notations & Description \\
\hline$i$ & Index of firms: manufacturer $(i=m)$, subsidiary $(i=d)$ or retailer $(i=r)$ \\
$j$ & Index of centralized $(j=C)$ or decentralized $(j=D)$ encroachment \\
$\lambda$ & Market base (the intercept of demand function) \\
$c$ & The coefficient of demand sensitivity for green innovation per unit product \\
$\theta$ & The manufacturer's direct sales cost for per unit product, $0 \leq c<a$ \\
$w_{r}$ & Green innovation effort made by the manufacturer \\
$w_{d}$ & Manufacturer's wholesale price for the retailer \\
$q_{i}$ & Manufacturer's transfer price for her subsidiary \\
$p_{i}$ & The product quantities of firm $i=d, r$ and $q_{i}>0$ \\
$\prod_{i}$ & The product's retail price of firm $i=d, r$ and $p_{i}>w_{i}>0$
\end{tabular}

Under centralized encroachment, the manufacturer and the retailer compete in quantities in the market, both of which are rational and pursue the maximization of their interests. The game sequence of centralized encroachment is as follows: At stage 1, the manufacturer determines the wholesale price and the level of her green innovation efforts. At stage 2, the manufacturer and the retailer jointly choose their respective sales volumes. With decentralized encroachment, the manufacturer leaves the retail decision to its sale subsidiary, and the subsidiary and retailer compete quantitatively in the market to maximize their own interests. The game order of decentralized encroachment is as follows: At stage 1, the manufacturer determines the wholesale price of the retailer, the transfer price of the 
subsidiary and the level of green innovation efforts. Then, at stage 2, the subsidiary and the retailer decide on their respective sales quantities at the same time.

\subsection{Assumptions}

To establish the appropriate models, we make the following assumptions:

- The manufacturer and the retailer compete in the market for quantities while the environmentally aware consumers are willing to pay a higher price for products with higher green quality. To characterize these features, we follow similar widely adopted demand functions $[8,33-35]$ to depict the retail prices for products $d$ and $r$ as follows:

$$
p_{d}=a-q_{d}-k q_{r}+\lambda \theta, p_{r}=a-q_{r}-k q_{d}+\lambda \theta
$$

where $a$ is the initial market potential, $\theta$ stands for the manufacturer's efforts in green innovation, $p_{i}$ is the retail price for per unit green product $i=d, r, q_{i}$ is the order quantities for per unit green product $i=d, r$. The cross-price sensitivity coefficient $k$ is less than its price-sensitivity coefficient, i.e., $0 \leq k \leq 1[33,34]$. In extreme cases, the value of $k=0$ reflects that the two competing products are completely independent. $\lambda$ represents the green preference coefficient of the consumers. The larger it is, the higher the price that consumers are willing to pay for green products.

- Compared with non-green products, the manufacturer will invest more in green innovation, such as low-carbon storage technology, solar technology and new energy vehicle technology. This is often in the form of fixed costs. For tractability, we consider a second-order cost function $h=\frac{u \theta^{2}}{2}$ to represent the green innovation investment, where $u>0$ is the cost coefficient of the investment. It can be seen that the investment cost of the green product is a convex function of green innovation efforts, that is, the cost of green input increases with the level of the green innovation effort, which is consistent with the practical industry operations. This function is commonly used in the literatures [35].

- In addition to the cost of green investment, the manufacturer will also incur the cost of producing products. To avoid the trivial, we assume the manufacturer's unit production cost is not related with product green innovation and set it to zero. We use $c(0 \leq c<a)$ to represent the manufacturer's unit selling cost while the retailer's unit selling cost is normalized to zero, indicating the retailer has cost advantage in retailing. The retailer's sales advantage comes from a better understanding of customer's preferences and more direct contact with the customers [30].

- To make our paper realistic and without loss of generality, we assume the green investment cost is sufficiently high, i.e., $u>0$ (see the Proofs of Lemmas 1 and 2).

- We assume that the manufacturers and retailers are completely rational, pursuing the maximization of their respective interests. In the research of many scholars, firms often seek to maximize their profits as their objectives [36].

\section{The Equilibrium Results}

\subsection{Centralized Encroachment}

Under centralized encroachment, the manufacturer first decides the retailer's wholesale price $\left(w_{r}\right)$ and the level of green innovation efforts $(\theta)$, and then, the manufacturer and the retailer choose their retail quantities $\left(q_{d}\right.$ and $\left.q_{r}\right)$ to maximize their own profits. Given this decision sequence, to ensure sub-game perfection, the game is solved using backward induction.

Given the manufacturer's wholesale price and green innovation efforts, the manufacturer solves the following profit-maximization problem:

$$
\operatorname{Max}_{q_{d}} \prod_{m}\left(q_{d}, q_{r}, \theta, w_{r}\right)=w_{r} q_{r}+\left(p_{d}-c\right) q_{d}-\frac{u \theta^{2}}{2}
$$


In Equation (2), $w_{r} q_{r}$ represents the manufacturer's wholesale profit and $\left(p_{d}-c\right) q_{d}$ denotes the manufacturer's retail profit. Similarly, the profit-maximization problem of the retailer can be given by

$$
\operatorname{Max}_{q_{r}} \prod_{r}\left(q_{d}, q_{r}, w_{r}\right)=\left(p_{r}-w_{r}\right) q_{r}
$$

Solving Equations (2) and (3) simultaneously, the retail quantities of the manufacturer $\left(q_{d}\right)$ and the retailer $\left(q_{r}\right)$ can be obtained as follows:

$$
\begin{aligned}
& q_{d}^{C}\left(\theta, w_{r}\right)=\frac{2(a-c)-a k+(2-k) \lambda \theta+k w_{r}}{4-k^{2}} \\
& q_{r}^{C}\left(\theta, w_{r}\right)=\frac{2 a-2 w_{r}-(a-c) k+(2-k) \lambda \theta}{4-k^{2}}
\end{aligned}
$$

Intuitively, Equations (4) and (5) reveal that the direct selling cost depresses the quantities in the direct channel but stimulates the quantities in the wholesale channel. Thus, the existence of direct selling cost is helpful to alleviate manufacturer encroachment to some extent. On the other hand, it implies that the retailer can still survive in the market despite the manufacturer reaching the end consumers through direct sale channel. As a matter of fact, instead of replacing the retailer, the manufacturer seeks to maximize the total profits in two channels.

Anticipating Equations (4) and (5), the manufacturer decides the wholesale price $\left(w_{r}\right)$ and green innovation efforts $(\theta)$ simultaneously to maximize the sum of retail and wholesale profits:

$$
\operatorname{Max}_{w_{r}, \theta} \prod_{m}\left(q_{d}^{C}\left(\theta, w_{r}\right), q_{r}^{C}\left(\theta, w_{r}\right), \theta, w_{r}\right)
$$

Substituting Equations (4) and (5) into Equation (6), solving the first-order conditions of Equation (6) reveals the manufacturer's equilibrium wholesale price and the green innovation efforts. Then, we put them back to get the equilibrium results under centralized encroachment, which are summarized as follows.

Lemma 1. Under centralized encroachment, when $c<\widehat{c}=\frac{a u(2-k)(4+k)}{\left(8-k^{2}\right) u-(2-k) \lambda^{2}}$, the equilibrium green innovation efforts, price, retail quantities and profits are the following:

$$
\begin{aligned}
\theta^{C}= & \frac{\lambda\left[(2-k)(6-k) a-\left(8-4 k+k^{2}\right) c\right]}{2 u\left(8-3 k^{2}\right)-(2-k)(6-k) \lambda^{2}}, \quad w_{r}^{C}=\frac{\left[4\left(2-k^{2}\right) a+(a-c) k^{3}\right] u-2(2-k) c \lambda^{2}}{2\left(8-3 k^{2}\right) u-(2-k)(6-k) \lambda^{2}}, \\
q_{d}^{C}= & \frac{\left[(2-k)(4+k) a-\left(8-k^{2}\right) c\right] u+(2-k) c \lambda^{2}}{2\left(8-3 k^{2}\right) u-(2-k)(6-k) \lambda^{2}}, q_{r}^{C}=\frac{4[(1-k) a+c k)] u-2 c \lambda^{2}}{2\left(8-3 k^{2}\right) u-(2-k)(6-k) \lambda^{2}}, \\
& \Pi_{m}^{C}=\frac{\left[(2-k)(2-6) a^{2}-2\left(8-4 k+k^{2}\right) c a+\left(8+k^{2}\right) c^{2}\right] u-2 c^{2} \lambda^{2}}{2\left[2\left(8-3 k^{2}\right) u-(2-k)(6-k) \lambda^{2}\right]}, \text { and } \\
& \Pi_{r}^{C}=\frac{4\left\{2 u[(1-k) a+c k]-c \lambda^{2}\right\}^{2}}{\left[2\left(8-3 k^{2}\right) u-(2-k)(6-k) \lambda^{2}\right]^{2}} .
\end{aligned}
$$

Otherwise, when $c \geq \widehat{c}$, the manufacturer will not use this encroachment strategy.

Lemma 1 shows that whether the strategy of centralized encroachment can be used depends on the encroachment cost. Only when the encroachment cost is less than a threshold, the manufacturer can encroach into the end market. Otherwise, she has to rely on the retailer to sell her green products. Next, we shall discuss the effect of consumer green awareness.

Proposition 1. Under centralized encroachment, the equilibrium green innovation efforts $\left(\theta^{C}\right)$, wholesale price $\left(w_{r}^{C}\right)$, sales quantities $\left(q_{i}^{C}\right)$ and profits $\left(\Pi_{m}^{C}\right.$ and $\left.\Pi_{r}^{C}\right)$ all increase with the consumer green awareness.

From Proposition 1, the greater the green preference of the consumers, i.e., the stronger the consumer environmental awareness, they are more inclined to buy green products, and 
it stimulates the demand for products with higher greenness. Certainly, the manufacturer is incentivized to make more green innovation efforts. Then, the increasing green innovation efforts incur higher research and development costs, and thus, the manufacturer will raise wholesale prices for green products to maximize her profits, and the retailer will set higher retail price accordingly. As a result, both the manufacturer and the retailer will benefit from increasing consumer green awareness.

Proposition 2. Under centralized encroachment, the level of green innovation efforts $\left(\theta^{C}\right)$ decreases with the product substitutability $(k)$.

Proposition 2 suggests that as the competition between the manufacturer and the retailer increases, the manufacturer tends to reduce green innovation efforts. The reason is that increasing competition will force the manufacturer to reduce her prices. To maximize the profits, the manufacturer will choose to reduce the green innovation investment to save the producing costs. In other words, the costs of increasing green innovation are greater than the benefits, which thereby curb the manufacturer's green innovation efforts.

Proposition 3. Under centralized encroachment, as the product substitutability, $k$, increases:

(a) If $c<c_{1}$, both players' profits will decrease;

(b) If $c_{1}<c<c_{2}$, the manufacturer's profit will decrease while the retailer's profit will increase, where $c_{1}$ and $c_{2}$ are provided in Appendix A;

(c) If $c_{2}<c<\widehat{c}$, both players' profits will increase.

It can be seen from Proposition 3 that as the product substitutability increases, the change of both players' profits critically depends on the unit encroachment cost. The threshold of the encroachment cost is affected by several factors such as the consumer green awareness, the cost-coefficient of green innovation efforts, the product substitutability, and market demand. From Proposition 3(a), when the manufacturer's encroachment is sufficiently cost-efficient $\left(c<c_{1}\right.$ ), both players suffer from increasing product substitutability. This is intuitive because the manufacturer is easy to fall into face-to-face competition with the retailer for low encroachment cost.

From Proposition 3(b), when the encroachment cost is in an intermediate range $\left(c_{1}<c<c_{2}\right)$, increasing product substitutability hurts the manufacturer but benefits the retailer. The reason is that compared with the low encroachment cost, the higher encroachment cost will curb the manufacturer's direct sales and soften the competition with the retailer, which boosts the demand in the wholesale market. As the market becomes more competitive, the retailer benefits more from the increasing wholesale demand. However, from the manufacturer's perspective, she still suffers from the increasing competition because the growing benefit from the wholesale market is not enough to cover the loss caused by the reduction of direct channel sales.

Proposition 3(c) suggests that both players always prefer to the higher product substitutability when the encroachment is highly costly. The reason, again, is that the manufacturer's encroachment in this case is so difficult that she turns to extend the wholesale market. This effect benefits both the manufacturer and the retailer especially when the products between the two channels become more substitutable and more competitive.

\subsection{Decentralized Encroachment}

We now move on to study the decentralized encroachment. Under decentralization, the manufacturer first sets the wholesale price for the retailer, the transfer price for the subsidiary and the green innovation efforts. Then, the retailer and the subsidiary compete in the market to determine their respective retail quantities. We solve the game by backward induction. 
Given the manufacturer's wholesale and transfer prices, the retailer's retail decision under decentralized encroachment is the same as that in Equation (3) under centralized encroachment. The subsidiary solves the following profit maximization problem:

$$
\operatorname{Max}_{q_{d}} \prod_{d}\left(q_{d}, q_{r}, w_{d}\right)=\left(p_{d}-w_{d}-c\right) q_{d}
$$

By solving Equations (3) and (7) simultaneously, the retail quantities, $q_{d}$ and $q_{r}$, of the subsidiary and the retailer can be given by

$$
\begin{aligned}
& q_{d}^{D}\left(\theta, w_{r}, w_{d}\right)=\frac{2(a-c)-2 w_{d}-a k+k \mathrm{w}_{r}+(2-k) \lambda \theta}{4-k^{2}}, \\
& q_{r}^{D}\left(\theta, w_{r}, w_{d}\right)=\frac{(2-k) a-2 w_{r}+c k+k w_{d}+(2-k) \lambda \theta}{4-k^{2}} .
\end{aligned}
$$

As expected, the subsidiary's retail quantities decrease with the transfer price and the encroachment cost while the retailer's retail quantities increase with these parameters. Compared with Equations (4) and (5) under centralized encroachment, in addition to the encroachment cost, the transfer price imposes a double-marginalization effect on the direct channel, which conveys a less aggressive posture to the retailer and thus may increase his market share.

Given the responses in Equations (8) and (9), the manufacturer decides the wholesale price $\left(w_{r}\right)$, transfer price $\left(w_{d}\right)$ and green innovation efforts to maximize the sum of retail and wholesale profits:

$$
\operatorname{Max}_{w_{r}, w_{d}, \theta} \prod_{m}\left(q_{d}^{D}\left(\theta, w_{r}, w_{d}\right), q_{r}^{D}\left(\theta, w_{r}, w_{d}\right), \theta, w_{r}, w_{d}\right) .
$$

Substituting Equations (8) and (9) into Equation (10), the first-order conditions of Equation (10) are solved to obtain the optimal wholesale price, transfer price and green innovation efforts. Then, we substitute them back and derive the equilibrium results for decentralized encroachment, as indicated in the following lemma.

Lemma 2. Under decentralized encroachment, when $c<\breve{c}=\frac{2 a u(2-k)}{4 u-\lambda^{2}}$, the equilibrium green innovation efforts, prices, quantities and profits are the following:

$$
\begin{aligned}
& \theta^{D}=\frac{\lambda[(3-2 k) a-(2-k) c]}{2 u\left(2-k^{2}\right)-\lambda^{2}(3-2 k)} \\
& w_{r}^{D}=\frac{2 u a\left(2-k^{2}\right)-c \lambda^{2}(2-k)}{2\left[2 u\left(2-k^{2}\right)-\lambda^{2}(3-2 k)\right]}, w_{d}^{D}=\frac{k\left[2 u(a-a k+c k)-c \lambda^{2}\right]}{2\left[2 u\left(2-k^{2}\right)-\lambda^{2}(3-2 k)\right]}, \\
& q_{d}^{D}=\frac{2 u(2 a-2 c-a k)+c \lambda^{2}}{2\left[2 u\left(2-k^{2}\right)-\lambda^{2}(3-2 k)\right]}, \quad q_{r}^{D}=\frac{2 u(a-a k+c k)-c \lambda^{2}}{2\left[2 u\left(2-k^{2}\right)-\lambda^{2}(3-2 k)\right]}, \\
& \Pi_{m}^{D}=\frac{2 u\left[(3-2 k) a^{2}-2 a c(2-k)+2 c^{2}\right]-c^{2} \lambda^{2}}{4\left[2 u\left(2-k^{2}\right)-\lambda^{2}(3-2 k)\right]} \text {, and } \Pi_{r}^{D}=\frac{\left[2 u(a-a k+c k)-c \lambda^{2}\right]^{2}}{4\left[2 u\left(2-k^{2}\right)-\lambda^{2}(3-2 k)\right]^{2}} \text {. }
\end{aligned}
$$

Otherwise, when $c \geq \breve{c}$, the manufacturer will not use the decentralized encroachment strategy.

Similar to the equilibriums in Lemma 1 under centralized encroachment, Lemma 2 clearly demonstrates that the manufacturer still chooses to encroach into the end market only when the direct selling cost is below a threshold. A difference lies in the threshold value shifting from $\widehat{c}$ to $\breve{c}$. We can verify:

$$
\breve{c}-\widehat{c}=-\frac{a u k(2-k)\left[2 u(k+2)-3 \lambda^{2}\right]}{\left(\lambda^{2}-4 u\right)\left[u\left(k^{2}-8\right)+(2-k) \lambda^{2}\right]}<0 .
$$

This comparison implies that the manufacturer can use the centralized encroachment strategy in a greater range than the decentralized one. This is because the transfer price between subsidiaries under decentralization strengthens the double marginalization in direct channel, which in turn increases the difficulty of the manufacturer encroachment. 
Proposition 4. Under decentralized encroachment, the green innovation efforts $\left(\theta^{D}\right)$, wholesale price $\left(w_{r}^{D}\right)$, transfer price $\left(w_{d}^{D}\right)$, retail quantities $\left(q_{r}^{D}\right.$ and $\left.q_{d}^{D}\right)$ and profits $\left(\Pi_{r}^{D}\right.$ and $\left.\Pi_{m}^{D}\right)$ all increase with the consumer green awareness.

Proposition 4 shows that consumer green awareness has a positive effect on the decisions under decentralized encroachment, which is consistent with the results of centralized encroachment. More specifically, as consumer green awareness increases, the manufacturer will make more green innovation efforts to produce greener products and charge higher prices for the retailer and the subsidiary. Moreover, both the retailer and the subsidiary can sell greener products in the end markets. Because of aforesaid reasons, both the manufacturer and the retailer end up earning more profits.

We next discuss the effect of product substitutability and have the following propositions.

Proposition 5. Under decentralized encroachment, the green innovation efforts $\left(\theta^{D}\right)$ decrease with the products substitutability ( $k$ ).

This proposition is similar to Proposition 2, indicating that the more intense the competition, the less is the green innovation effort made by the manufacturer. As such, increasing product competition will induce the manufacturer to reduce green innovation and produce products with lower greenness to save the costs.

Proposition 6. Under decentralized encroachment, as the product substitutability, $k$, increases:

(a) If $c<\breve{c}$, the manufacturer's profit will decrease;

(b) If $c<c_{3}$, the retailer's profit will decrease; if $c_{3}<c<\breve{c}$, it will increase, where $c_{3}$ is provided in Appendix A.

Proposition 6 exhibits that the effect of product substitutability on each player's profitability is related with the encroachment cost. These results under decentralized encroachment are similar to those in Proposition 3 under centralized encroachment except for different thresholds. In particular, as the product substitutability increases, when the encroachment cost is small enough $\left(c<c_{3}\right)$, the manufacturer can make full use of the direct channel to initiate stronger competition with the retailer so that both parties are worse off. When the encroachment cost is in the middle range $\left(c_{3}<c<c\right)$, it is not easier for the manufacturer to sell through direct channel, and she in turn relies more on the retailer to rake in more profit, which instead benefits the retailer. When the encroachment cost is sufficiently large $\left(c_{3}<c<\widehat{c}\right)$, the direct channel is suppressed, but the wholesale channel is efficiently expended. In this case, the retailer achieves higher profitability from extending the wholesale market. It is worthy to note that the manufacturer is always hurt due to increasing competition. The reasons are as follows: First, for the case of low encroachment cost, when the product substitutability increases, as mentioned above, the manufacturer will rely more on the direct channel but limit the wholesale market. This channel conflict leads to the manufacturer's profit loss. Second, as shown in Equation (11), the manufacturer's decentralized encroachment needs to lower the threshold of the encroachment cost, which makes it impossible for the manufacturer to increase her profit by softening the channel competition.

Interestingly, we find that the threshold of the retailer's benefit under decentralized encroachment is lower than that under centralized encroachment, i.e., $c_{3}<c_{1}$. It indicates that the retailer under decentralized encroachment can benefit from stronger competition in a more efficient way in comparison with centralized encroachment. The underlying reason is again the double marginalization caused by the transfer price under decentralized encroachment. This double-marginalization effect in direct channel acts as a part of encroachment costs and thus reduces the encroachment threshold values. 


\section{Centralized vs. Decentralized Encroachment}

With the equilibrium outcomes under centralized and decentralized encroachments on hand, we compare them and have the following proposition.

Proposition 7. (a) The transfer price under decentralized encroachment is set above marginal cost, i.e., $w_{d}^{D}>0$;

(b) The manufacturer's retail quantity is lower under decentralized encroachment, i.e., $q_{d}^{D}<q_{d}^{C}$, while the retailer's retail quantity is higher under decentralized encroachment, i.e., $q_{r}^{D}>q_{r}^{C}$;

(c) The level of green innovation efforts is higher under decentralized encroachment, i.e., $\theta^{D}>\theta^{C}$;

(d) The wholesale price is higher under decentralized encroachment, i.e., $w_{r}^{D}>w_{r}^{C}$.

Proposition 7(a) demonstrates that the transfer price under decentralized encroachment is set above marginal cost. In fact, the manufacturer signals to the retailer that she is less aggressive in the retail competition. As reflected in Proposition 7(b), this posture is detrimental to the manufacturer's retail market, but it enhances the demand in the wholesale realm. By convincing the retailer that the manufacturer will not take a more competitive strategy, decentralized encroachment induces the manufacturer to make more green innovation efforts in Proposition 7(c) and charge higher wholesale price in Proposition 7(d). Due to the greener products, environmentally aware consumers are willing to pay higher prices (we can check that $p_{d}^{D}>p_{d}^{C}$ and $p_{r}^{D}>p_{r}^{C}$ ). Although higher pricing reduces the loss imposed in retail profits, there are two significant aforementioned benefits in the wholesale market: higher selling price and more retail quantities. Thus, a stronger boost in wholesale profit $\left(w_{r}^{D} q_{r}^{D}>w_{r}^{C} q_{r}^{C}\right)$ may provide a benefit for both players. We have the following proposition.

Proposition 8. Under decentralized encroachment, both the manufacturer and the retailer benefit, i.e., $\Pi_{m}^{D}>\Pi_{m}^{C}, \Pi_{r}^{D}>\Pi_{r}^{C}$.

Proposition 8 shows that the strategy of decentralized encroachment is beneficial to both the manufacturer and the retailer. From Proposition 7, the manufacturer's wholesale quantity increases while her retail quantity decreases under decentralized encroachment. The resulting total profit increases, indicating that the manufacturer's profit in the wholesale channel is enough to cover the loss of the retail channel. Therefore, when producing green products, the manufacturer prefers to adopt the strategy of decentralized encroachment.

In addition to evaluate the economic goals, we further investigate the societal and environmental performance. In this paper, the social welfare is considered in the comparisons of centralized and decentralized encroachments. Typically, consumer surplus, known as net income of consumers, refers to the difference between the willingness of all consumers to pay for a certain number of products and the actual total price paid. Consumer surplus measures the extra benefits that consumers believe they have gained [37]. Based on the above explanation, firms (the manufacturer and the retailer) in supply chain seek economic benefits and provide green products to increase consumer surplus. However, their operations also produce emissions and pollutions, which are detrimental to the environment. To reflect these effects and consistent with previous literature [37-39], social welfare consists of total profits of all supply chain parties, consumer surplus and environmental damage impact. Under the encroachment structure $j=C, D$, each element is calculated as follows.

(1) Supply chain profit $S C^{j}$. The supply chain profit in this study is equal to the total profits of the two stakeholders, i.e., the manufacturer and the retailer. It is

$$
S C^{j}=\Pi_{m}^{j}+\Pi_{r}^{j}=\left(a-q_{d}^{j}-k q_{r}^{j}+\lambda \theta^{j}-c\right) q_{d}^{j}+\left(a-q_{r}^{j}-k q_{d}^{j}+\lambda \theta^{j}\right) q_{r}^{j}-\frac{u\left(\theta^{j}\right)^{2}}{2} .
$$


(2) Consumer Surplus $C S^{j}$. Consumers buy green products and enjoy the surpluses, which equal to the price increment between the maximum acceptable price and the actual price. It can be given by

$$
C S^{j}=\frac{1}{2}\left(q_{d}^{j}+q_{r}^{j}\right)^{2} .
$$

(3) Environmental damage $E D^{j}$. From Proposition 7(c), decentralized encroachment provides the higher level of green innovation efforts than centralized one. To avoid trivial results and similar to [5], we take the green innovation efforts $\left(\theta^{D}\right)$ under decentralized encroachment as a benchmark, where the environmental damage is normalized to zero $\left(E D^{D}=0\right)$ relative to that under centralized encroachment. We use the parameter $d$ to denote the environmental damage cost of per unit product reduction of green innovation efforts made by the manufacturer, which measures the level of environmental impact because of greenness decline. A larger $d$ shows a higher degree of the manufacturer's production damage to the environment. The environmental damage under centralized encroachment can be formulated by

$$
E D^{C}=\frac{1}{2} d\left(\theta^{D}-\theta^{C}\right)\left(q_{d}^{C}+q_{r}^{C}\right)^{2} .
$$

We use a quadratic damage function to characterize decreasing marginal returns due to the fact that additional production will produce more environmental pollution. This treatment is also widely used in the extant literature [37-40]. To sum up, social welfare under each encroachment strategy $j=C, D$ can be given as follows.

$$
S W^{j}=S C^{j}+C S^{j}-E D^{j} .
$$

By comparing the social welfare under centralized and decentralized encroachments, we have the following proposition.

Proposition 9. Compared with centralized encroachment:

(a) Environmental damage under decentralized encroachment is lower, i.e., $E D^{D}<E D^{C}$;

(b) If $d \leq d^{*}$, the social welfare under decentralized encroachment is lower, i.e., $S W^{D} \leq S W^{C}$; if $d>d^{*}$, the social welfare under decentralized encroachment is higher, i.e., $S W^{D}>S W^{C}$, where $d^{*}$ is provided in Appendix A.

Proposition 9(a) indicates that the environmental damage under decentralized encroachment is lower than that under centralized encroachment. This thanks to the higher level of green innovation efforts led by decentralized encroachment. Proposition 9(b) shows that when the cost coefficient of environmental damage is sufficiently large, decentralized encroachment has the potential to prominently reduce the environmental damage and thereby leads to higher total social welfare. Therefore, from the perspective of environmental and societal performances, the government can make policies, such as reward and punishment mechanisms, to incentive the manufacturers to adopt decentralized encroachment to produce greener products.

\section{Numerical Studies}

In this section, we use some numerical examples to discuss the impacts of some key factors on the member's profit improvement and social welfare due to centralized vs. decentralized encroachment. These key factors include consumer green awareness $(\lambda)$, product substitutability $(k)$ and cost factor of environment damage $(d)$. Similar to the extant literature $[7,20,41,42]$, in order to simplify the calculation and make the value in the corresponding interval, we set the parameter values as follows: $a=10, \mu=4, c=2$. We can verify that the setting of these parameter values meets the basic assumptions of our model, such as positive demands and profits. 


\subsection{Effect of Consumer Green Awareness ( $\lambda$ ) on Profits}

We first analyze the effect of consumer green awareness on profits. To this end, we set $k=0.8$ and vary $\lambda$ from $0-1$. For ease of expressions, we denote firm $i$ 's profit improvement between decentralized and centralized encroachments by $\Delta \Pi_{i}=\Pi_{i}^{D}-\Pi_{i}^{C}, i=m, r$. In this setting, we illustrate the effect of consumer green awareness on each player's profit improvement in Figure 1 where (a) and (b) show the effect of consumer green awareness on the manufacturer's and the retailer's profit, respectively.

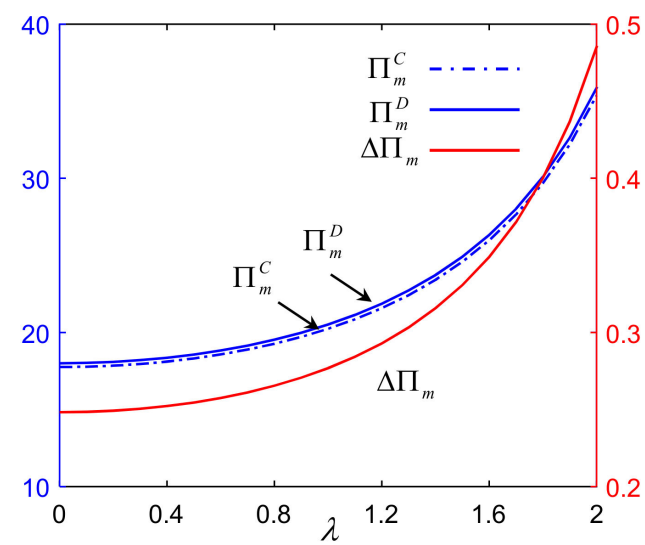

(a) Manufacturer's profit

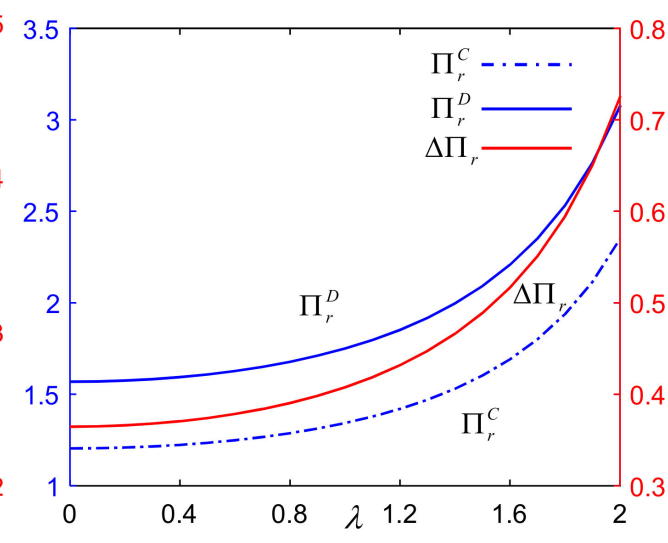

(b) Retailer's profit

Figure 1. The effect of $\lambda$ on each party's profit improvement.

From Figure 1, we can see that as $\lambda$ increases, the profits of both the manufacturer and the retailer under either centralized or decentralized encroachment will increase. These results verify the rightness of Propositions 1 and 4 . More importantly, the profit improvements of both the manufacturer and the retailer due to decentralized encroachment increase with $\lambda$. In other words, both supply chain members can benefit more from decentralized encroachment when consumer green awareness grows. Therefore, firms are incentivized to adopt the preferred decentralization strategy under the environment of advocating green consumptions.

\subsection{Effect of Product Substitutability ( $k$ ) on Profits}

To examine the effects of the product substitutability $(k)$, we choose $c=0.1$ and 5 to represent the low and high levels of the encroachment cost. Let $\lambda=1$ and fix the other parameters as before. Figures 2 and 3 plot the results, where (a) and (b) show the results when $c=0.1$ and $c=5$, respectivelyFirst, for the case of low encroachment cost $(c=0.1)$, we observe that the profits of both the manufacturer and the retailer under each regime decrease with $k$. These results are consistent with Propositions 3 and 6 . For high encroachment $\operatorname{cost}(c=5)$, the manufacturer's profit under each regime also decreases with $k$. The reason is $\breve{c}<c_{2}$, indicating that when the encroachment cost is sufficiently high, the manufacturer will not choose to use the direct channel. To ensure the manufacturer's encroachment, we still set the high encroachment cost lower than the threshold, i.e., $\breve{c}>5$. Figure 3b shows that the retailer's profit under decentralized encroachment will increase as $k$ becomes sufficiently large. This implies that the encroachment cost is very high such that $c>c_{3}$. These results are also in line with Proposition 6 . 


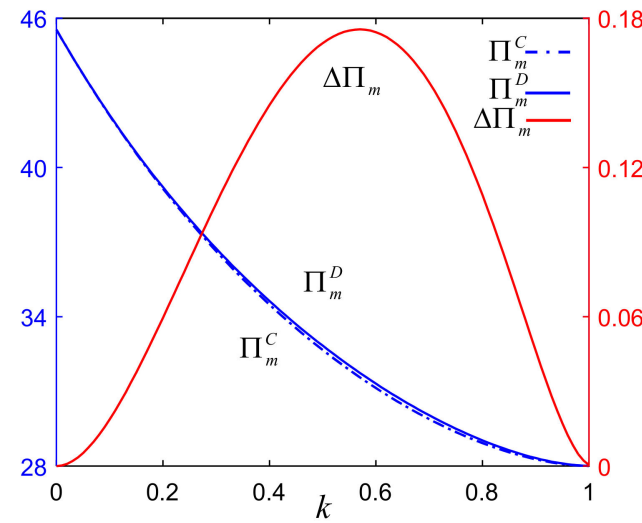

(a) $c=0.1$

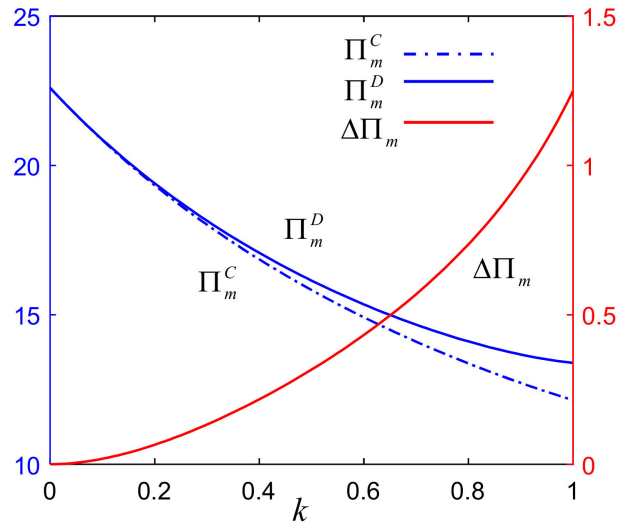

(b) $c=5$

Figure 2. The effect of $k$ on the manufacturer's profit improvement.

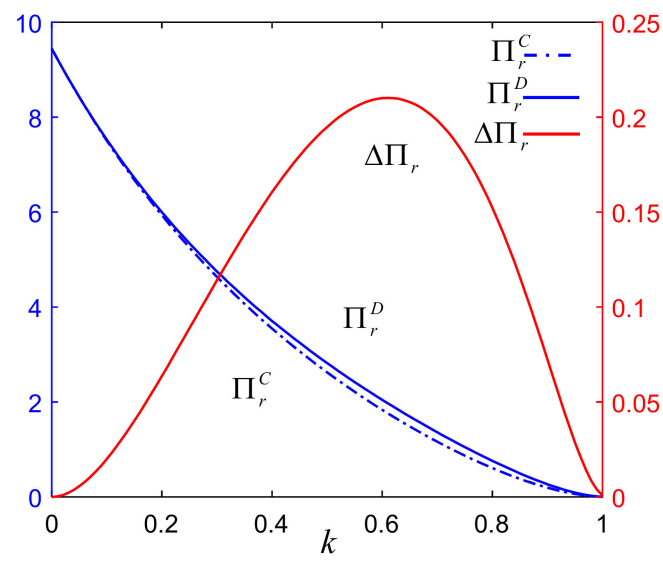

(a) $c=0.1$

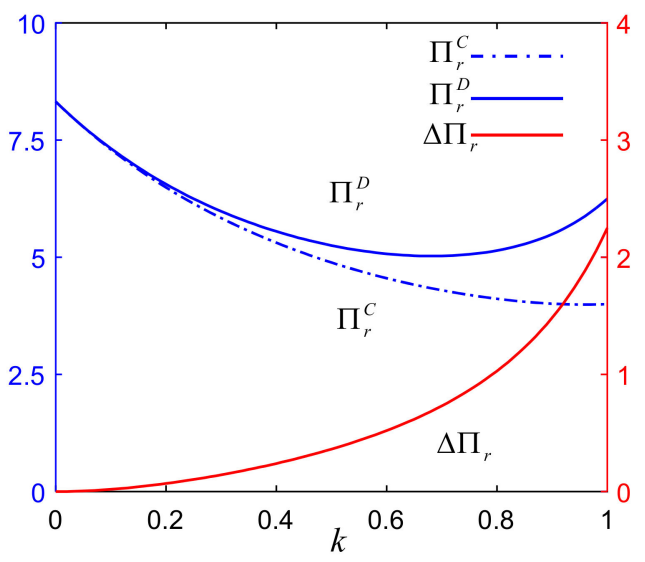

(b) $c=5$

Figure 3. The effect of $k$ on the retailer's profit improvement.

Second, for the case of low encroachment cost $(c=0.1)$, it can be seen that as $k$ increases, both players' profit improvements due to decentralized encroachment first increase and then decrease. To explain this, note that the manufacturer can efficiently use her direct channel in this setting. The benefit of decentralized encroachment lies in allowing the manufacturer to convey reduced competitiveness to increase the wholesale demand. When $k=0$, the two channels are independent, and thus, there is no difference between these two strategies. As $k$ increases, the competition becomes fiercer, and thus, the decentralized encroachment can reap the wholesale profit more. However, if $k$ is very large, the manufacturer under decentralized encroachment will reduce the transfer price to deal with the stiff competition, which makes decentralized encroachment close to the centralized one. Specifically, in the extreme case of $k=1$, strong competition will induce the manufacturer to exclude the retailer, which leads to equal profits between these two strategies.

Third, when the encroachment cost is high $(c=5)$, it is not easy for the manufacturer to encroach into the retail market, and thus, the manufacturer will rely more on the wholesale market. Figures $2 \mathrm{~b}$ and $3 \mathrm{~b}$ show that both players' profit improvements due to decentralized encroachment increase with $k$. This means that due to the role of softened competition played by decentralized encroachment, when the retailer benefits from the increasing wholesale market, the manufacturer can also benefit from increasing dependence on it for the case of high encroachment cost. In summary, we observe that each member's profit improvement due to decentralized encroachment is always positive. These results verify that Proposition 8 holds as well. 


\subsection{Effect of $\lambda, k$ and $d$ on Social Welfares}

We next compare the social welfares between centralized and decentralized encroachments and study how the parameters affect their difference. For convenience, we define $\Delta S W=S W^{D}-S W^{C}$. Figure 4 is drawn to show these results, where (a) shows the effect of $\lambda$ when $k=0.8$ and $d=10$, (b) shows the effect of $k$ when $\lambda=2$ and $d=10$, and (c) illustrates the effect of $d$ when $\lambda=2$ and $k=0.8$. First, as $\lambda$ increases, social welfare under either centralized or decentralized encroachment also increases. This implies that higher consumer green awareness not only benefits the firms in the supply chain but only benefits both the environment and the society. Moreover, the higher the consumer green awareness, the more the social welfare improvement due to decentralized encroachment. Therefore, in addition to promoting green consumption, policy makers also need to encourage the manufacturer to adopt decentralized direct channels in sales.

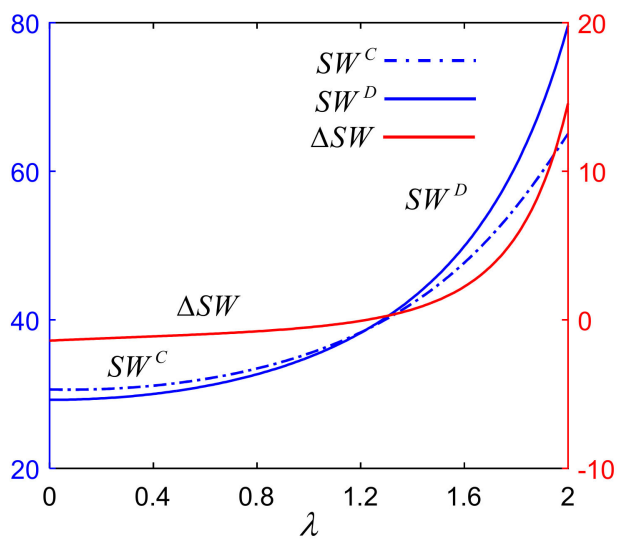

(a) Effect of $\lambda(k=0.8, d=10)$

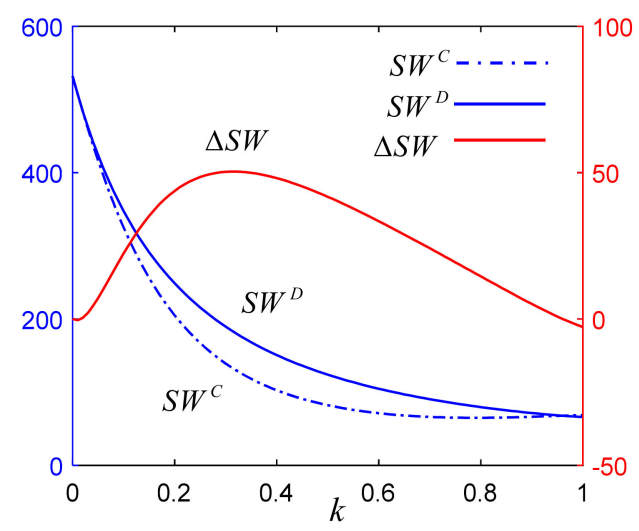

(b) Effect of $k(\lambda=2, d=10)$

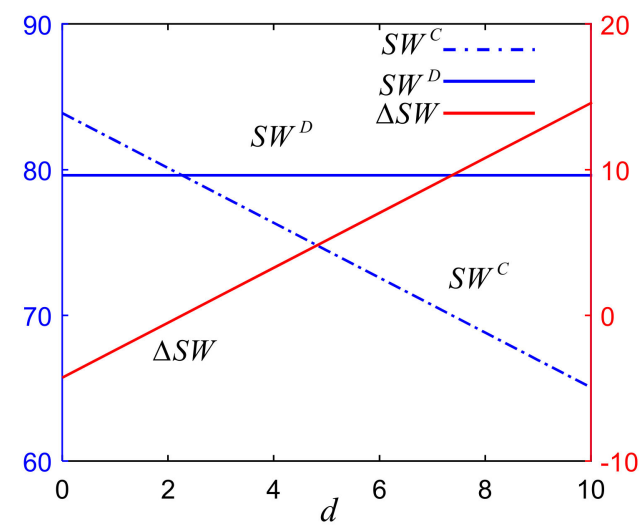

(c) Effect of $d(\lambda=2, k=0.8)$

Figure 4. The effect of $\lambda, k$ and $d$ on social welfare's improvement.

Second, Figure $4 \mathrm{~b}$ shows increasing product substitutability $(k)$ has a negative effect on social welfare under each regime. This is because channel competition reduces both supply chain members' profits as indicated in Figures 2 and 3. However, it is interesting to find that as $k$ increases, the social welfare's improvement under decentralized encroachment first increases and then decreases. We have the following reasons. When the encroachment cost is not high $(c=2)$, as reflected in Figures 2 and 3, the profit improvement of both players also first increases and then decreases with $k$. For $k$ sufficiently large, the level of green innovation efforts under decentralized encroachment will decrease and closely reach to that under centralized encroachment. Moreover, increasing competition under centralized encroachment is helpful to restore the demand, which in turn leads to more consumer surplus. That is why the social welfare's improvement will decrease as $k$ is large 
enough. At the extremes, when $k$ is close to 1 , centralized encroachment is preferred in social welfare.

Finally, the environmental damage coefficient has a positive effect on social welfare's improvement in a linear way. Consistent with Proposition 9, when $d$ exceeds a threshold, the manufacturer under decentralized encroachment will make more green innovation efforts to increase the product greenness, and subsequently reduce the harm to the environment. As a result, the total social welfare under decentralized encroachment will also increase accordingly.

\section{Conclusions}

The rapid development of green supply chain management and e-commerce enables a large number of supply chain enterprises to sell green products. In addition, many traditional manufacturers have established online direct sale channels to increase demand and profits. In this dual-channel supply chain, the upstream manufacturer's direct sale channel encroaches into the retailer's markets, which inevitably affects the downstream retailer's and consumers' decision-making. As a result, manufacturer encroachment may reduce the retailer's market and hurt the retailer $[32,43,44]$. Because of induced lower wholesale price and increased demand, the encroachment may also benefit the manufacturer and the retailer $[18,45,46]$. So far, the manufacturer has two types of encroachment strategies, namely, centralized and decentralized encroachments. Prior studies commonly pay more attention on centralized encroachment, where the manufacturer makes centralized retail decisions on behalf of his subsidiary. In contrast, under decentralized encroachment, the manufacturer charges a transfer price to his subsidiary and permits the subsidiary to make its own retail decisions. Despite decentralized encroachment being widely adopted in business reality, the related studies on it are still limited.

We make a major contribution to studying what encroachment strategy drives green innovation and analyze the effects of consumer green awareness and product substitutability on the manufacturer's choice between centralized and decentralized encroachments. Our analysis and main findings are summarized as follows: (1) Under each encroachment strategy, increasing consumer green awareness incentives the manufacturer to put in more efforts in green innovation. This also benefits both the manufacturer and the retailer. (2) Under each encroachment strategy, as the channel competition between the manufacturer and the retailer intensifies, the manufacturer will reduce her green innovation efforts. (3) Under centralized encroachment, when the encroachment cost is relatively low, higher product substitutability will hurt both the manufacturer and the retailer. In contrast, when the encroachment cost is high, both parties can benefit from the increasing product substitutability. (4) The effect of product substitutability on profits under decentralized encroachment has a similar pattern to that under centralized encroachment. A difference is that due to the less threshold value of encroachment cost, the manufacturer under decentralization is always worse off as the product substitutability increases. (5) Decentralization is more efficient to drive the manufacturer's green innovation than centralization. Moreover, decentralization benefits both the manufacturer and the retailer in profitability. (6) Because of a higher level of green innovation efforts, decentralization reduces the environmental damage in comparison with centralization. When the environment damage cost is sufficiently high, decentralization is also preferred in social welfare.

According to the above results, we can provide meaningful managerial insights and policy suggestions for firms and policymakers. In the context of supply chain sustainability and profitability, when the firms participate in green innovation, decentralization is a promising alternative to conventional centralization strategy. Although centralization is proved to be perfect for eliminating double marginalization $[12,23,47]$, our study demonstrates that decentralization with an appropriate transfer price above marginal cost can convey softened retail competition between the manufacturer and the retailer, which best balances the profitability from the wholesale and retail markets. This leads to higher green innovation and consequently benefits both parties. Therefore, the government can devise 
various policies, such as monetary subsidies and/or taxations for environmentally friendly activities [38,48-50], to inspire the adoption of decentralization among supply chain firms in green innovations.

We acknowledge that our models have some limitations. Therefore, the following studies may need to be further explored in the future. First, the competition between green products and ordinary products can be considered in the multi-channel supply chains. Secondly, research under asymmetric information can be incorporated in the model. Third, contracts/policies can be considered, such as government subsidies and revenue sharing.

Author Contributions: Conceptualization and methodology, J.L. and G.L.; formal analysis, D.C. and R.M.; writing - original draft preparation, J.L., G.L. and R.M.; writing-review and editing, D.C., J.L. and G.L.; supervision, D.C., J.L. and R.M. All authors have read and agreed to the published version of the manuscript.

Funding: This research received no external funding.

Institutional Review Board Statement: Not applicable.

Informed Consent Statement: Not applicable.

Data Availability Statement: The data used to support the findings of this study are available upon request.

Acknowledgments: This project was co-sponsored by the National Social Science Foundation of China (19BGL194), the Zhejiang Provincial Natural Science Foundation of China (LY20G020006 and LQ19G030007) and the Zhejiang Gongshang University on-line and off-line Hybrid Teaching Reform Project (1010XJ2919103).

Conflicts of Interest: The authors declare no conflict of interest.

\section{Appendix A. Proofs}

Proof of Lemma 1. Under centralized encroachment, the game is solved by backward induction. At the second stage, the second derivatives of the manufacturer and the retailer are given by

$$
\frac{\partial \prod_{m}^{2}}{\partial^{2} q_{d}}=\frac{\partial \prod_{r}^{2}}{\partial^{2} q_{r}}=-2<0
$$

Hence, $\prod_{m}$ and $\prod_{r}$ are concave in $q_{d}$ and $q_{r}$, respectively. Then, the first-order conditions associated with Equations (2) and (3) jointly yield unique equilibrium quantities as a function of the wholesale price and product green degree, as those in Equations (4) and (5).

At the first stage, the Hessian matrix of the manufacturer's profit function in Equation (6) is given as follows:

$$
H=\left(\begin{array}{cc}
\frac{6 k^{2}-16}{\left(k^{2}-4\right)^{2}} & \frac{\lambda\left(k^{3}-4 k^{2}+8\right)}{\left(k^{2}-4\right)^{2}} \\
\frac{\lambda\left(k^{2}-2 k-4\right)}{(k-2)(k+2)^{2}} & \frac{u\left(4 k+8-2 k^{2}-k^{3}\right)+\lambda^{2}(2 k-4)}{(k-2)(k+2)^{2}}
\end{array}\right)
$$

The leading principal minors are the following:

$$
\left|H_{1}\right|=\frac{6 k^{2}-16}{\left(k^{2}-4\right)^{2}} \text { and }\left|H_{2}\right|=-\frac{\lambda^{2}\left(k^{2}-8 k+12\right)+2 u\left(3 k^{2}-8\right)}{\left(k^{2}-4\right)^{2}} \text {. }
$$

The Hessian matrix is negative definite if $\left|H_{1}\right|<0$ and $\left|H_{2}\right|>0$. In order to satisfy the two aforementioned conditions, the equation $u>\frac{3}{4} \lambda^{2}$ must be ensured. Therefore, the condition $u>\frac{3}{4} \lambda^{2}$ is considered to maintain the concavity of the manufacturer's profit function.

By solving the first-order derivatives of $\frac{\partial \Pi_{m}}{\partial w_{r}}=0$ and $\frac{\partial \Pi_{m}}{\partial \theta}=0$, we obtain the unique optimal $w_{r}^{C}$ and $\theta^{C}$. Substituting them into Equations (4) and (5), we have the quantities of $q_{d}^{C}$ and $q_{r}^{C}$. 


$$
q_{d}^{C}=\frac{\left[(2-k)(4+k) a-\left(8-k^{2}\right) c\right] u+(2-k) c \lambda^{2}}{2\left(8-3 k^{2}\right) u-(2-k)(6-k) \lambda^{2}}, q_{r}^{C}=\frac{4[(1-k) a+c k)] u-2 c \lambda^{2}}{2\left(8-3 k^{2}\right) u-(2-k)(6-k) \lambda^{2}} .
$$

We define:

$$
\widehat{c}=\frac{a u(2-k)(4+k)}{\left(8-k^{2}\right) u-(2-k) \lambda^{2}} .
$$

Note that $q_{d}^{C}(\widehat{c})=0$ and

$$
\frac{\partial q_{d}^{C}}{\partial c}=-\frac{\left(8-k^{2}\right) u-(2-k) \lambda^{2}}{2\left(8-3 k^{2}\right) u-(2-k)(6-k) \lambda^{2}}<0 .
$$

Hence, we know that $q_{d}^{c}>0$ for $c<\widehat{c}$. Similarly, we can verify that when $c<\widehat{c}$, demand and profits in equilibrium are positive, which is the necessary conditions for Nash equilibrium. Substituting them back, we can obtain all the equilibrium outcomes as indicated in Lemma 1 , for $c<\widehat{c}$.

When $c \geq \widehat{c}$, the direct selling cost is so high that the manufacturer chooses to close her direct channel. In this case, the manufacturer just relies on the retailer to sell her products and does not use the encroachment strategy. This completes the proof.

Proof of Proposition 1. The first order conditions of $q_{d}^{C}, q_{r}^{C}, w_{r}^{C}, \theta^{C}, \Pi_{m}^{C}, \Pi_{r}^{C}$ with respect to $\lambda$ are respectively shown as follows:

$$
\begin{gathered}
\frac{d q_{d}^{C}}{d \lambda}=\frac{2 \lambda u\left(k^{2}+2 k-8\right)\left(8 c-12 a+8 a k-4 c k-a k^{2}+c k^{2}\right)}{\left[(2-k)(6-k) \lambda^{2}-2 u\left(8-3 k^{2}\right)\right]^{2}}, \\
\frac{d q_{r}^{C}}{d \lambda}=\frac{8 \lambda u(k-1)\left(8 c-12 a+8 a k-4 c k-a k^{2}+c k^{2}\right)}{\left[(2-k)(6-k) \lambda^{2}-2 u\left(8-3 k^{2}\right)\right]^{2}}, \\
\frac{d w_{r}^{C}}{d \lambda}=\frac{2 \lambda u\left(4 k^{2}-k^{3}-8\right)\left(8 c-12 a+8 a k-4 c k-a k^{2}+c k^{2}\right)}{\left[(2-k)(6-k) \lambda^{2}-2 u\left(8-3 k^{2}\right)\right]^{2}}, \\
\frac{d \theta^{C}}{d \lambda}=\frac{-\left(8 c-12 a+8 a k-4 c k-a k^{2}+c k^{2}\right)\left[k^{2} \lambda^{2}+u\left(16-6 k^{2}\right)+\lambda^{2}(12-8 k)\right]}{\left[(2-k)(6-k) \lambda^{2}-2 u\left(8-3 k^{2}\right)\right]^{2}}, \\
\frac{d \Pi_{m}^{C}}{d \lambda}=\frac{2 \lambda u\left(8 c-12 a+8 a k-4 c k-a k^{2}+c k^{2}\right)^{2}}{\left[(2-k)(6-k) \lambda^{2}-2 u\left(8-3 k^{2}\right)\right]^{2}}, \\
\frac{d \Pi_{r}^{C}}{d \lambda}=\frac{32 \lambda u(k-1)\left[c \lambda^{2}-2 u(a-a k+c k)\right]\left(8 c-12 a+8 a k-4 c k-a k^{2}+c k^{2}\right)}{\left[(2-k)(6-k) \lambda^{2}-2 u\left(8-3 k^{2}\right)\right]^{3}} .
\end{gathered}
$$

As $0<k<1$ and $u>\frac{3 \lambda^{2}}{4}$, the following conditions are satisfied:

$8 c-12 a+8 a k-4 c k-a k^{2}+c k^{2}<0, \quad c \lambda^{2}-2 u(a-a k+c k)<0, \quad$ and $(2-k)(6-k) \lambda^{2}-2 u\left(8-3 k^{2}\right)<0$.

Hence, we have $\frac{d q_{d}^{C}}{d \lambda}>0, \frac{d q_{r}^{C}}{d \lambda}>0, \frac{d w_{r}^{C}}{d \lambda}>0, \frac{d \theta^{C}}{d \lambda}>0, \frac{d \Pi_{m}^{C}}{d \lambda}>0$ and $\frac{d \Pi_{r}^{C}}{d \lambda}>0$. This completes the proof.

Proof of Proposition 2. The first order derivative of $\theta^{C}$ with respect to $k$ are shown as follows:

$$
\frac{d \theta^{C}}{d k}=\frac{4 \lambda H_{1}}{\left[(2-k)(6-k) \lambda^{2}-2 u\left(8-3 k^{2}\right)\right]^{2}},
$$

where $H_{1}=16 c u-32 \alpha u+4 c \lambda^{2}+6 c k^{2} u-c k^{2} \lambda^{2}+44 \alpha k u-32 c k u+2 c k \lambda^{2}-12 \alpha k^{2} u$.

The first and second order derivative of $H_{1}$ with respect to $k$ are shown as follows: 


$$
\begin{gathered}
\frac{d H_{1}}{d k}=4 u(11 a-8 c-6 a k+3 c k)+2 c \lambda^{2}(1-k), \\
\frac{d^{2} H_{1}}{d k^{2}}=-\left[2 c \lambda^{2}+12 u(2 a-c)\right]<0 .
\end{gathered}
$$

So, as $k$ increases, the first order derivative of $H_{1}$ will decrease. When $k=1$, $\frac{d H_{1}}{d k}=20 u(a-c)>0$. Hence, $\frac{d H_{1}}{d k}>0$, which means that as $k$ increase, $H_{1}$ will increase. Specifically, when $k=1, H_{1}=5 c\left(\lambda^{2}-2 c u\right)<0$. Therefore, we conclude that $H_{1}<0$ and $\frac{d \theta^{C}}{d k}<0$. This completes the proof.

Proof of Proposition 3. The first order derivative of $\Pi_{r}^{C}$ with respect to $k$ are shown as follows:

$$
\frac{d \Pi_{r}^{C}}{d k}=\frac{-16\left[c \lambda^{2}-2 u(a-\alpha k+c k)\right] H_{2}}{\left[(2-k)(6-k) \lambda^{2}-2 u\left(8-3 k^{2}\right)\right]^{3}},
$$

where $H_{2}=16 a u^{2}-4 c \lambda^{4}-16 c u^{2}-4 a \lambda^{2} u+12 c \lambda^{2} u+6 a k^{2} u^{2}-6 c k^{2} u^{2}+c k \lambda^{4}-12 a k u^{2}-2 a k \lambda^{2} u$ $+6 c k \lambda^{2} u+a k^{2} \lambda^{2} u-c k^{2} \lambda^{2} u$.

We can see that $(2-k)(6-k) \lambda^{2}-2 u\left(8-3 k^{2}\right)<0$ and $c \lambda^{2}-2 u(a-\alpha k+c k)<0$. So, the sign of $\frac{d \Pi_{r}^{C}}{d k}$ is opposite to that of $H_{2}$.

The first-order condition of $\mathrm{H}_{2}$ with respect to $c$ is:

$$
\frac{d H_{2}}{d c}=-2\left(8+3 k^{2}\right) u^{2}+\left(12+6 k-k^{2}\right) u-(4-k) \lambda^{4}<0 .
$$

It means $\mathrm{H}_{2}$ decreases with $c$. We define

$$
c_{1}=\frac{a u\left[2\left(3 k^{2}-6 k+8\right) u-\left(4+2 k-k^{2}\right) \lambda^{2}\right]}{2\left(3 k^{2}+8\right) u^{2}-\left(12+6 k-k^{2}\right) \lambda^{2} u+(4-k) \lambda^{4}} .
$$

When $c=c_{1}, H_{2}=0$.

Comparing $\widehat{c}$ and $c_{1}$, we have

$$
\widehat{c}-c_{1}=\frac{\left\{\begin{array}{c}
2 a u\left[4 k\left(3 k^{2}-8\right) u^{2}+2\left(k^{3}+k^{2} \lambda^{2}-12 k^{2}+12 k-8 \lambda^{2}+16\right) \lambda^{2} u\right. \\
\left.-\left(k^{2}+2 k \lambda^{2}-10 k-4 \lambda^{2}+16\right) \lambda^{4}\right]
\end{array}\right\}}{\left[u\left(k^{2}-8\right)+(2-k) \lambda^{2}\right]\left[2\left(3 k^{2}+8\right) u^{2}+\left(k^{2}-6 k-12\right) \lambda^{2} u+(4-k) \lambda^{4}\right]}>0 .
$$

It follows that if $c<c_{1}, H_{2}>0$; if $c_{1}<c<\widehat{c}, H_{3}<0$. Hence, we know if $c<c_{1}$, $\frac{d \Pi_{r}^{C}}{d k}<0$; if $c_{1}<c<\widehat{c}, \frac{d \Pi_{r}^{C}}{d k}>0$.

The first-order derivative of $\Pi_{m}^{C}$ with respect to $k$ are shown as follows:

$$
\frac{d \Pi_{m}^{C}}{d k}=\frac{-2\left[c \lambda^{2}-2 u(a-a k+c k)\right] H_{3}}{16\left[2 u\left(k^{2}-2\right)+\lambda^{2}(3-2 k)\right]^{2}}
$$

where $H_{3}=16 c u-16 a u-4 c \lambda^{2}+6 a k u+c k \lambda^{2}$.

We can see that the sign of $\frac{d \Pi_{m}^{C}}{d k}$ depends on that of $H_{3}$. When $c=c_{2}=\frac{2 a u(8-3 k)}{16 u+(k-4) \lambda^{2}}$, $H_{3}=0$. Next, we compare $\widehat{c}$ and $c_{2}$ in the following:

$$
\widehat{c}-c_{2}=\frac{a u k\left[2\left(3 k^{2}-8\right) u+\left(k^{2}-8 k+12\right) \lambda^{2}\right]}{\left(16 u+k \lambda^{2}-4 \lambda^{2}\right)\left[\left(k^{2}-8\right) u+(2-k) \lambda^{2}\right]}>0 .
$$

Moreover, $\frac{d H_{3}}{d c}=16 u-\lambda^{2}(4-k)>0$. This indicates that $H_{3}$ increases with $c$. When $c<c_{2}, H_{3}<0$; when $c_{2}<c<\widehat{c}, H_{3}>0$. Hence, when $c<c_{2}, \frac{d \Pi_{m}^{c}}{d k}<0$; when $c_{2}<c<\widehat{c}, \frac{d \Pi_{m}^{C}}{d k}>0$. 
Now, comparing $c_{1}$ and $c_{2}$, we have

$$
c_{1}-c_{2}=\frac{a u\left[6 k u-(4-k) \lambda^{2}\right]\left[2\left(3 k^{2}-8\right) u+\left(k^{2}-8 k+12\right) \lambda^{2}\right]}{\left[16 u+(k-4) \lambda^{2}\right]\left[2\left(3 k^{2}+8\right) u^{2}+\left(k^{2}-6 k-12\right) \lambda^{2} u+(4-k) \lambda^{4}\right]}<0 .
$$

This follows that $c_{1}<c_{2}<\widehat{c}$.

In summary, based on above results, we have: if $c<c_{1}, \frac{d \Pi_{m}^{C}}{d k}<0$ and $\frac{d \Pi_{r}^{C}}{d k}<0$; if $c_{1}<c<c_{2}, \frac{d \Pi_{m}^{C}}{d k}<0$ and $\frac{d \Pi_{r}^{C}}{d k}>0$; if $c_{2}<c<\widehat{c}, \frac{d \Pi_{m}^{C}}{d k}>0$ and $\frac{d \Pi_{r}^{C}}{d k}>0$. This completes the proof.

Proof of Lemma 2. With decentralized encroachment, we again use backward induction to solve the game. At the second stage, the second conditions of the profit functions are

$$
\frac{\partial \prod_{m}^{2}}{\partial^{2} q_{d}}=\frac{\partial \prod_{r}^{2}}{\partial^{2} q_{r}}=-2<0 .
$$

Therefore, $\prod_{m}$ and $\prod_{r}$ are concave in $q_{d}$ and $q_{r}$, respectively, which guarantees the uniqueness of the optimal retail quantities as shown in Equations (8) and (9).

Then, at the first stage, the Hessian matrix obtained from the manufacturer's profit function is calculated as follows:

$$
H=\left(\begin{array}{ccc}
\frac{2\left(3 k^{2}-8\right)}{\left(k^{2}-4\right)^{2}} & \frac{2 k\left(2-k^{2}\right)}{\left(k^{2}-4\right)^{2}} & \frac{\lambda\left(k^{2}-2 k-4\right)}{(k-2)(k+2)^{2}} \\
\frac{2 k\left(2-k^{2}\right)}{\left(k^{2}-4\right)^{2}} & \frac{4\left(k^{2}-2\right)}{\left(k^{2}-4\right)^{2}} & \frac{k^{2} \lambda}{(k-2)(k+2)^{2}} \\
\frac{\lambda\left(k^{2}-2 k-4\right)}{(k-2)(k+2)^{2}} & \frac{k^{2} \lambda}{(k-2)(k+2)^{2}} & \frac{u\left(-k^{2}-4 k-4\right)+2 \lambda^{2}}{(k+2)^{2}}
\end{array}\right)
$$

The leading principal minors are $\left|H_{1}\right|=\frac{2\left(3 k^{2}-8\right)}{\left(k^{2}-4\right)^{2}}, \quad\left|H_{2}\right|=\frac{4\left(2-k^{2}\right)}{\left(k^{2}-4\right)^{2}}$ and $\left|H_{3}\right|=\frac{2\left[2 u\left(k^{2}-2\right)+\lambda^{2}(3-2 k)\right]}{(k-2)(k+2)^{2}}$. The Hessian matrix is negative definite if $\left|H_{1}\right|<0$, $\left|H_{2}\right|>0,\left|H_{3}\right|<0$. In order to meet these mentioned conditions, the equation $2\left[2 u\left(k^{2}-2\right)+\lambda^{2}(3-2 k)\right]<0$ must be established. Therefore, the condition $2\left[2 u\left(k^{2}-2\right)+\lambda^{2}(3-2 k)\right]<0$ is considered to maintain the concavity of the profit function for manufacturer. Since $u>\frac{3 \lambda^{2}}{4}, \prod_{m}$ is jointly concave in $w_{r}$ and $w_{d}$ and $\theta$. Solving the first order derivatives $\frac{\partial \Pi_{m}}{\partial w_{r}}=0, \frac{\partial \Pi_{m}}{\partial w_{d}}=0, \frac{\partial \Pi_{m}}{\partial \theta}=0$, we derive the corresponding equilibrium prices and product green degree as follows.

$$
\begin{gathered}
w_{r}^{D}=\frac{2 u a\left(2-k^{2}\right)-c \lambda^{2}(2-k)}{2\left[2 u\left(2-k^{2}\right)-\lambda^{2}(3-2 k)\right]}, w_{d}^{D}=\frac{k\left[2 u(a-a k+c k)-c \lambda^{2}\right]}{2\left[2 u\left(2-k^{2}\right)-\lambda^{2}(3-2 k)\right]}, \\
\theta^{D}=\frac{\lambda[(3-2 k) a-(2-k) c]}{2 u\left(2-k^{2}\right)-\lambda^{2}(3-2 k)} .
\end{gathered}
$$

Substituting them into Equations (8) and (9), the equilibrium quantities are given by:

$$
q_{d}^{D}=\frac{2 u(2 a-2 c-a k)+c \lambda^{2}}{2\left[2 u\left(2-k^{2}\right)-\lambda^{2}(3-2 k)\right]}, q_{r}^{D}=\frac{2 u(a-a k+c k)-c \lambda^{2}}{2\left[2 u\left(2-k^{2}\right)-\lambda^{2}(3-2 k)\right]} .
$$

We define a threshold $\breve{c}$ so that $q_{d}^{D}(c=\breve{c})=0$, where $\breve{c}=\frac{2 a u(2-k)}{4 u-\lambda^{2}}$.

Note that $\frac{\partial q_{d}^{D}}{\partial c}=-\frac{4 u-\lambda^{2}}{2\left[2 u\left(2-k^{2}\right)-\lambda^{2}(3-2 k)\right]}<0$.

It follows that $q_{d}^{D}>0$ for $c<\breve{c}$. In a similar way, we can prove that when $c<\widetilde{c}$, demand and profits in equilibrium are positive, which is the necessary conditions for Nash equilibrium. Using substitution, for $c<\breve{c}$, the equilibrium outcomes are derived as shown in Lemma 2. 
When $c \geq \breve{c}$, the manufacturer will close the direct channel because of very high encroachment cost. In other words, the manufacturer will turn to the single wholesale channel and not use decentralized encroachment strategy. This completes the proof.

Proof of Proposition 4. The first order derivatives of $q_{d}^{D}, q_{r}^{D}, w_{r}^{D}, \theta^{D}, \Pi_{m}^{D}$ and $\Pi_{r}^{D}$ with respect to $\lambda$ are shown as follows:

$$
\begin{gathered}
\frac{d q_{d}^{D}}{d \lambda}=\frac{2 \lambda u(2-k)[(3-2 k) a-(2-k) c]}{\left[2 u\left(2-k^{2}\right)-\lambda^{2}(3-2 k)\right]^{2}}, \frac{d q_{r}^{D}}{d \lambda}=\frac{2 \lambda u(1-k)[(3-2 k) a-(2-k) c]}{\left[2 u\left(2-k^{2}\right)-\lambda^{2}(3-2 k)\right]^{2}}, \\
\frac{d w_{d}^{D}}{d \lambda}=\frac{2 k \lambda u(1-k)[(3-2 k) a-(2-k) c]}{\left[2 u\left(2-k^{2}\right)-\lambda^{2}(3-2 k)\right]^{2}}, \frac{d w_{r}^{D}}{d \lambda}=\frac{2 \lambda u\left(2-k^{2}\right)[(3-2 k) a-(2-k) c]}{\left[2 u\left(2-k^{2}\right)-\lambda^{2}(3-2 k)\right]^{2}}, \\
\frac{d \theta^{D}}{d \lambda}=\frac{[(3-2 k) a-(2-k) c]\left[(3-2 k) \lambda^{2}+2\left(2-k^{2}\right) u\right]}{\left[2 u\left(2-k^{2}\right)-\lambda^{2}(3-2 k)\right]^{2}} \\
\frac{d \Pi_{m}^{D}}{d \lambda}=\frac{\lambda u[(3-2 k) a-(2-k) c]^{2}}{\left[2 u\left(2-k^{2}\right)-\lambda^{2}(3-2 k)\right]^{2}} \\
\frac{d \Pi_{r}^{D}}{d \lambda}=\frac{2 \lambda u(1-k)[(3-2 k) a-(2-k) c]\left[2 u(a-a k+c k)-c \lambda^{2}\right]}{\left[2 u\left(2-k^{2}\right)-\lambda^{2}(3-2 k)\right]^{3}}
\end{gathered}
$$

Similar to the Proposition 1, we have $\frac{d q_{d}^{D}}{d \lambda}>0, \frac{d q_{r}^{D}}{d \lambda}>0, \frac{d w_{r}^{D}}{d \lambda}>0, \frac{d \theta^{D}}{d \lambda}>0, \frac{d \Pi_{m}^{D}}{d \lambda}>0$, $\frac{d \Pi_{r}^{D}}{d \lambda}>0$. This completes the proof.

Proof of Proposition 5. The first order derivative of $\theta^{D}$ with respect to $k$ are shown as follows:

$$
\frac{d \theta^{D}}{d k}=\frac{-\lambda H_{3}}{\left[2 u\left(2-k^{2}\right)-\lambda^{2}(3-2 k)\right]^{2}},
$$

where $H_{3}=8 a u-4 c u-c \lambda^{2}-2 c k^{2} u-12 a k u+8 c k u+4 a k^{2} u$.

We get: $\frac{d H_{3}}{d k}=4 u(2 c-3 a+2 a k-c k), \frac{d^{2} H_{3}}{d k^{2}}=4 u(2 a-c)>0$.

Similar to the Proposition 2, we have $H_{3}>0$ and $\frac{d \theta^{D}}{d k}<0$. This completes the proof.

Proof of Proposition 6. The first-order condition of $\Pi_{m}^{D}$ with respect to $k$ is the following:

$$
\frac{d \Pi_{m}^{D}}{d k}=-\frac{\left[2 u(a-a k+c k)-c \lambda^{2}\right]\left[2 a u(2-k)-\left(4 u-\lambda^{2}\right) c\right]}{2\left[2 u\left(2-k^{2}\right)-\lambda^{2}(3-2 k)\right]^{2}} .
$$

It follows that $\frac{d \Pi_{m}^{D}}{d k}<0$, for $c<\breve{c}=\frac{2 a u(2-k)}{4 u-\lambda^{2}}$.

Similarly, the first-order condition of $\Pi_{r}^{D}$ with respect to $k$ is in the following.

$$
\frac{d \Pi_{r}^{D}}{d k}=\frac{\left[2 u(a-a k+c k)-c \lambda^{2}\right] H_{4}}{\left[2 u\left(2-k^{2}\right)-\lambda^{2}(3-2 k)\right]^{3}}
$$

where $H_{4}=c \lambda^{4}-4 a u^{2}+4 c u^{2}+a \lambda^{2} u-3 c \lambda^{2} u-2 a k^{2} u^{2}+2 c k^{2} u^{2}+4 a k u^{2}-2 c k \lambda^{2} u$.

We can see that the sign of $\frac{d \Pi_{r}^{D}}{d k}$ depends on that of $H_{4}$. We define a threshold $c_{3}$ so that $H_{5}\left(c=c_{3}\right)=0$, where $c_{3}=\frac{a u\left[2 u\left(k^{2}-2 k+2\right)-\lambda^{2}\right]}{2\left(k^{2}+2\right) u^{2}-(2 k+3) \lambda^{2} u+\lambda^{4}}$.

Comparing $c_{3}$ and $\breve{c}$, we have $c_{3}-\breve{c}=\frac{a u\left(2 k u-\lambda^{2}\right)\left[2 u\left(k^{2}-2\right)+(3-2 k) \lambda^{2}\right]}{\left(4 u-\lambda^{2}\right)\left[2\left(k^{2}+2\right) u^{2}-(2 k+3) \lambda^{2} u+\lambda^{4}\right]}<0$.

The first-order condition of $H_{4}$ with respect to $c$ is:

$$
\frac{d H_{4}}{d c}=2\left(k^{2}+2\right) u^{2}-(2 k+3) u \lambda^{2}+\lambda^{4}>0 .
$$


This indicates $H_{4}$ increases with $c$. Thus, if $c<c_{3}, H_{4}<0$; if $c_{3}<c<\breve{c}_{,} H_{4}>0$. It follows that if $c<c_{3}, \frac{d \Pi_{r}^{D}}{d k}<0$; if $c_{3}<c<\breve{c}, \frac{d \Pi_{r}^{D}}{d k}>0$. This completes the proof.

Proof of Proposition 7. (a) From lemma 2, $w_{d}^{D}=\frac{k\left[2 u(a-a k+c k)-c \lambda^{2}\right]}{2\left[2 u\left(2-k^{2}\right)-\lambda^{2}(3-2 k)\right]}>0$.

(b) Using $q_{d}^{D}$ and $q_{r}^{D}$ from Lemma 2 and $q_{d}^{C}$ and $q_{r}^{C}$ from Lemma 1,

$$
\begin{aligned}
q_{d}^{D}-q_{d}^{C} & =\frac{k(2-k)\left[-3 \lambda^{2}+2 u(2+k)\right]\left[c \lambda^{2}-2 u(a-a k+c k)\right]}{2\left[\lambda^{2}\left(k^{2}-8 k+12\right)+2 u\left(3 k^{2}-8\right)\right]\left[2 u\left(k^{2}-2\right)+\lambda^{2}(3-2 k)\right]}<0, \\
q_{r}^{D}-q_{r}^{C} & =\frac{k^{2}\left(\lambda^{2}-2 u\right)\left[c \lambda^{2}-2 u(a-a k+c k)\right]}{2\left[\lambda^{2}\left(k^{2}-8 k+12\right)+2 u\left(3 k^{2}-8\right)\right]\left[2 u\left(k^{2}-2\right)+\lambda^{2}(3-2 k)\right]}>0 .
\end{aligned}
$$

Hence, $q_{d}^{D}<q_{d}^{C}$ and $q_{r}^{D}>q_{r}^{C}$.

(c) Using $\theta^{D}$ from Lemma 2 and $\theta^{C}$ from Lemma 1,

$$
\theta^{D}-\theta^{C}=\frac{k^{2} \lambda(k-1)\left[c \lambda^{2}-2 u(a-a k+c k)\right]}{\left[\lambda^{2}\left(k^{2}-8 k+12\right)+2 u\left(3 k^{2}-8\right)\right]\left[2 u\left(k^{2}-2\right)+\lambda^{2}(3-2 k)\right]}>0 .
$$

Hence, $\theta^{D}>\theta^{C}$.

(d) Using $w_{r}^{D}$ from Lemma 2 and $w_{r}^{C}$ from Lemma 1,

$$
w_{r}^{D}-w_{r}^{C}=\frac{k^{2}\left[2 u\left(k^{2}-2\right)+\lambda^{2}(2-k)\right]\left[c \lambda^{2}-2 u(a-a k+c k)\right]}{2\left[\lambda^{2}\left(k^{2}-8 k+12\right)+2 u\left(3 k^{2}-8\right)\right]\left[2 u\left(k^{2}-2\right)+\lambda^{2}(3-2 k)\right]}>0 .
$$

Hence, $w_{r}^{D}>w_{r}^{C}$. This completes the proof.

Proof of Proposition 8. Using $\Pi_{m}^{D}$ and $\Pi_{r}^{D}$ from Lemma 2 and $\Pi_{m}^{C}$ and $\Pi_{r}^{C}$ from Lemma 1,

$$
\begin{gathered}
\Pi_{m}^{D}-\Pi_{m}^{C}=\frac{k^{2}\left[c \lambda^{2}-2 u(a-a k+c k)\right]^{2}}{4\left[\lambda^{2}\left(k^{2}-8 k+12\right)+2 u\left(3 k^{2}-8\right)\right]\left[2 u\left(k^{2}-2\right)+\lambda^{2}(3-2 k)\right]}>0, \\
\Pi_{r}^{D}-\Pi_{r}^{C}=\frac{k^{2}\left(\lambda^{2}-2 u\right)\left[c \lambda^{2}-2 u(a-a k+c k)\right]^{2}\left[\left(k^{2}-16 k+24\right) \lambda^{2}+2 u\left(7 k^{2}-16\right)\right]}{4\left[\lambda^{2}\left(k^{2}-8 k+12\right)+2 u\left(3 k^{2}-8\right)\right]^{2}\left[2 u\left(k^{2}-2\right)+\lambda^{2}(3-2 k)\right]^{2}}>0 .
\end{gathered}
$$

Hence, $\Pi_{m}^{D}>\Pi_{m}^{C}$ and $\Pi_{r}^{D}>\Pi_{r}^{C}$. This completes the proof.

Proof of Proposition 9. (a) From (14), we know: $E D^{D}=0, E D^{C}=\frac{1}{2} d\left(\theta^{D}-\theta^{C}\right)\left(q_{d}^{C}+q_{r}^{C}\right)^{2}$. Since $\theta^{D}-\theta^{C}>0$ from Proposition 7(c), we obtain $E D^{D}<E D^{C}$.

(b) From (15), for $j=C, D, S W^{j}=S C^{j}+C S^{j}-E D^{j}$. From Proposition 8, we can see $S C^{D}=\Pi_{m}^{D}+\Pi_{r}^{D}>S C^{C}=\Pi_{m}^{C}+\Pi_{r}^{C}$. Using $q_{d}^{D}$ and $q_{r}^{D}$ from Lemma 2 and $q_{d}^{C}$ and $q_{r}^{C}$ from Lemma 1,

$$
q_{m}^{D}+q_{r}^{D}-q_{m}^{C}-q_{r}^{C}=\frac{-k\left[c \lambda^{2}-2 u(a-a k+c k)\right]\left[u\left(k^{2}+k-4\right)+(3-2 k) \lambda^{2}\right]}{\left[\lambda^{2}\left(k^{2}-8 k+12\right)+2 u\left(3 k^{2}-8\right)\right]\left[2 u\left(k^{2}-2\right)+\lambda^{2}(3-2 k)\right]}<0 .
$$

Hence, from Equation (13), we have $C S^{D}<C S^{C}$. Comparing the social welfare under centralized and decentralized encroachments,

$$
S W^{D}-S W^{C}=S C^{D}-S C^{C}+C S^{D}-C S^{C}+\frac{1}{2} d\left(\theta^{D}-\theta^{C}\right)\left(q_{d}^{C}+q_{r}^{C}\right)^{2} .
$$

We define a threshold $d^{*}$ such that $S W^{D}=S W^{C}$ for $d=d^{*}$, where

$$
d^{*}=\frac{2\left(C S^{C}-C S^{D}+S C^{C}-S C^{D}\right)}{\left(\theta^{D}-\theta^{C}\right)\left(q_{d}^{C}+q_{r}^{C}\right)^{2}} .
$$


Therefore, we have if $d \leq d^{*}, S W^{D} \leq S W^{C}$; if $d>d^{*}, S W^{D}>S W^{C}$. This completes the proof.

\section{References}

1. Wang, K.; Wei, Y.M.; Huang, Z. Potential Gains from Carbon Emissions Trading in China: A DEA Based Estimation on Abatement Cost Savings. Omega 2016, 63, 48-59.

2. Ramanathan, U.; Bentley, Y.; Pang, G. The Role of Collaboration in the UK Green Supply Chains: An Exploratory Study of the Perspectives of Suppliers, Logistics and Retailers. J. Clean. Prod. 2014, 70, 231-241. [CrossRef]

3. Sarkis, J. A Strategic Decision Framework for Green Supply Chain Management. J. Clean. Prod. 2003, 11, 397-440. [CrossRef]

4. Linton, J.D.; Klassen, R.; Jayaraman, V. Sustainable Supply Chains: An Introduction. J. Oper. Manag. 2007, 25, 1075-1082. [CrossRef]

5. Hong, Z.; Guo, X. Green Product Supply Chain Contracts Considering Environmental Responsibilities. Omega 2019, 83, 155-166. [CrossRef]

6. Basiri, Z.; Heydari, J. A Mathematical Model for Green Supply Chain Coordination with Substitutable Products. J. Clean. Prod. 2017, 145, 232-249. [CrossRef]

7. Hong, P.; Jagani, S.; Kim, J.; Youn, S.H. Managing Sustainability Orientation: An Empirical Investigation of Manufacturing Firms. Int. J. Prod. Econ. 2019, 211, 71-81. [CrossRef]

8. Li, B.; Hou, P.-W.; Chen, P.; Li, Q.-H. Pricing Strategy and Coordination in a Dual Channel Supply Chain with a Risk-Averse Retailer. Int. J. Prod. Econ. 2016, 178, 154-168. [CrossRef]

9. Conrad, K. Price Competition and Product Differentiation when Consumers Care for the Environment. Environ. Resour. Econ. 2005, 31, 1-19. [CrossRef]

10. Reinhardt, F.L. Environmental Product Differentiation: Implications for Corporate Strategy. Calif. Manag. Rev. 1998, 40, 43-73. [CrossRef]

11. Thøgersen, J. Eco-labeling is one among a number of policy tools that are used in what. In New Tools for Environmental Protection: Education, Information, and Voluntary Measures; Dietz, T., Stern, P.C., Eds.; National Academy Press: Washington, DC, USA, 2002; pp. 83-104.

12. Ranjan, A.; Jha, J.K. Pricing and Coordination Strategies of a Dual-Channel Supply Chain Considering Green Quality and Sales Effort. J. Clean. Prod. 2019, 218, 409-424. [CrossRef]

13. Yoon, D. Supplier Encroachment and Investment Spillovers. Prod. Oper. Manag. 2016, 25, 1839-1854. [CrossRef]

14. Li, T.T.; Xie, J.X.; Zhao, X.B. Supplier Encroachment in Competitive Supply Chains. Int. J. Prod. Econ. 2015, 165, 120-131. [CrossRef]

15. Sony Sells a Portion of Its Shares in StylingLife Holdings. Available online: https://www.sony.net/SonyInfo/News/Press/2006 12/06-114E/index.html (accessed on 27 April 2021).

16. Kalnins, A. An Empirical Analysis of Territorial Encroachment Within Franchised and Company-Owned Branded Chains. Mark. Sci. 2004, 23, 476-489. [CrossRef]

17. Vinhas, A.S.; Anderson, E. How Potential Conflict Drives Channel Structure: Concurrent (Direct and Indirect) Channels. J. Mark. Res. 2005, 42, 507-515. [CrossRef]

18. Arya, A.; Mittendorf, B.; Yoon, D.-H. Friction in Related-Party Trade When a Rival Is Also a Customer. Manag. Sci. 2008, 54, 1850-1860. [CrossRef]

19. Patra, P. Distribution of Profit in a Smart Phone Supply Chain under Green Sensitive Consumer Demand. J. Clean. Prod. 2018, 192, 608-620. [CrossRef]

20. Liu, Z.L.; Anderson, T.D.; Cruz, J.M. Consumer Environmental Awareness and Competition in Two-Stage Supply Chains. Eur. J. Oper. Res. 2012, 218, 602-613. [CrossRef]

21. Green, K.W.G., Jr.; Zelbst, P.J.; Meacham, J.; Bhadauria, V.S. Green Supply Chain Management Practices: Impact on Performance. Supply Chain Manag. Int. J. 2012, 17, 290-305. [CrossRef]

22. Ghosh, D.; Shah, J. A Comparative Analysis of Greening Policies Across Supply Chain Structures. Int. J. Prod. Econ. 2012, 135, 568-583. [CrossRef]

23. He, J.; Lei, Y.; Fu, X. Do Consumer's Green Preference and the Reference Price Effect Improve Green Innovation? A Theoretical Model Using the Food Supply Chain as a Case. Int. J. Environ. Res. Public Health 2019, 16, 5007. [CrossRef] [PubMed]

24. Liu, X.; Du, W.; Sun, Y. Green Supply Chain Decisions Under Different Power Structures: Wholesale Price vs. Revenue Sharing Contract. Int. J. Environ. Res. Public Health 2020, 17, 7737. [CrossRef] [PubMed]

25. Lee, D. Who Drives Green Innovation? A Game Theoretical Analysis of a Closed-Loop Supply Chain under Different Power Structures. Int. J. Environ. Res. Public Health 2020, 17, 2274. [CrossRef]

26. Cai, G. Channel Selection and Coordination in Dual-Channel Supply Chains. J. Retail. 2010, 86, 22-36. [CrossRef]

27. Heydari, J.; Govindan, K.; Aslani, A. Pricing and Greening Decisions in a Three-Tier Dual Channel Supply Chain. Int. J. Prod. Econ. 2019, 217, 185-196. [CrossRef]

28. Fein, A.J.; Anderson, E. Patterns of Credible Commitments: Territory and Brand Selectivity in Industrial Distribution Channels. J. Mark. 1997, 61, 19-34. [CrossRef] 
29. Tsay, A.A.; Agrawal, N. Channel Conflict and Coordination in the E-Commerce Age. Production and Operations Management. Prod. Oper. Manag. 2009, 13, 93-110. [CrossRef]

30. Arya, A.; Mittendorf, B.; Sappington, D.E.M. The Bright Side of Supplier Encroachment. Mark. Sci. 2007, 26, 651-659. [CrossRef]

31. Li, Z.; Gilbert, S.M.; Lai, G. Supplier Encroachment Under Asymmetric Information. Manag. Sci. 2014, 60, 449-462. [CrossRef]

32. Ha, A.; Long, X.; Nasiry, J. Quality in Supply Chain Encroachment. Manuf. Serv. Oper. Manag. 2015, 18, 280-298. [CrossRef]

33. Cai, G.G.; Zhang, Z.G.; Zhang, M. Game Theoretical Perspectives on Dual Channel Supply Chain Competition with Price Dis-Counts and Pricing Schemes. Int. J. Prod. Econ. 2009, 117, 80-96. [CrossRef]

34. Chen, J.; Zhang, H.; Sun, Y. Implementing Coordination Contracts in a Manufacturer Stackelberg Dual-Channel Supply Chain. Omega 2012, 40, 571-583. [CrossRef]

35. Swami, S.; Shah, J. Channel Coordination in Green Supply Chain Management. J. Oper. Res. Soc. 2013, 64, f336-f351. [CrossRef]

36. Li, W.N.; Elsadany, A.A.; Zhou, W.; Zhu, Y.L. Global Analysis, Multi-Stability and Synchronization in a Competition Model of Public Enterprises with Consumer Surplus. Chaos Solitons Fractals 2021, 143, 110604. [CrossRef]

37. Pal, R.; Saha, B. Pollution Tax, Partial Privatization and Environment. Resour. Energy Econ. 2015, 40, 19-35. [CrossRef]

38. Bian, J.; Zhao, X. Tax or Subsidy? An analysis of Environmental Policies in Supply Chains with Retail Competition. Eur. J. Oper. Res. 2020, 283, 901-914. [CrossRef]

39. Spence, M. Product Differentiation and Welfare. Am. Econ. Rev. 1976, 66, 407-414.

40. Krass, D.; Nedorezov, T.; Ovchinnikov, A. Environmental Taxes and the Choice of Green Technology. Prod. Oper. Manag. 2013, 22, 1035-1055. [CrossRef]

41. Poyago-Theotoky, J. The Organization of R\&D and Environmental Policy. J. Econ. Behav. Organ. 2007, 62, 63-75.

42. Ouchida, Y.; Goto, D. Do Emission Subsidies Reduce Emission? In the Context of Environmental R\&D Organization. Econ. Model. 2014, 36, 511-516.

43. Bian, J.; Guo, X.; Li, K.W. Decentralization or Integration: Distribution Channel Selection under Environmental Taxation. Transp. Res. Part E Logist. Transp. Rev. 2018, 113, 170-193. [CrossRef]

44. Zhang, J.; Li, S.; Zhang, S.; Dai, R. Manufacturer Encroachment with Quality Decision under Asymmetric Demand Information. Eur. J. Oper. Res. 2019, 273, 217-236. [CrossRef]

45. Chiang, W.K.; Chhajed, D.; Hess, J.D. Direct Marketing, Indirect Profits: A Strategic Analysis of Dual-Channel Supply-Chain Design. Manag. Sci. 2003, 49, 1-20. [CrossRef]

46. Sun, X.; Tang, W.; Chen, J.; Li, S.; Zhang, J. Manufacturer Encroachment with Production Cost Reduction under Asymmetric Information. Transp. Res. Part E Logist. Transp. Rev. 2019, 128, 191-211. [CrossRef]

47. Li, J.; Liang, J.; Shi, V.; Wang, Q. The Benefit of Manufacturer Encroachment Considering Consumer's Environmental Awareness and Product Competition. Ann. Oper. Res. 2021, 3, 1-19.

48. Li, J.; Wang, F.; He, Y. Electric Vehicle Routing Problem with Battery Swapping Considering Energy Consumption and Carbon Emissions. Sustainability 2020, 12, 10537. [CrossRef]

49. Zhang, C.; Su, W.; Zeng, S.; Balezentis, T.; Herrera-Viedma, E. A Two-Stage Subgroup Decision-Making Method for Processing Large-Scale Information. Expert Syst. Appl. 2021, 171, 114586. [CrossRef]

50. Li, J.; Yi, L.; Shi, V.; Chen, X. Supplier Encroachment Strategy in the Presence of Retail Strategic Inventory: Centralization or Decentralization? Omega 2021, 98, 102213. [CrossRef] 